\title{
REAÇÃO DE ABOBRINHA (Qucurbita moschata DUCHESNE) AO VÍRUS DO MOSAICO DA MELANCIA RAÇA-1 (WMV-1)
}

\author{
MARCELO YUKIO KUABARA \\ Engenheiro Agrônomo
}

Orientador: Prof. Dr. CYRO PAULINO DA COSTA

Dissertação apresentada à Escóla Superior de Agricultura "Luiz de Queiroz", da Universidadè de São Paulo, para obtenção do título de Mestre em Agronomia, AREA DE CONCENTRAÇÃO: Genética e Melhoramento de Plantats.

PIRACICAB A

Estado de São Paulo - Brasil

Novembro, 1984 
. i.

Aos meus pais Massuo e Isabel

Aos meus irmãos Cristina, Inês e Fäbio

Ao meu cunhado Jorge,

Aos meus parentes,

DEDICO 
.ii. -: AGRADECIMENTOS. :-

Minha gratidão as seguintes pessoas e instituições que contribuíram para a realização deste trabalho:

- Ao Prof. Dr. Cyro Paulino da Costa por sua orientação segura, pelos seus ensinamentos, por sua amizade e pelo apoio e estímulo que sempré me tem dedica do.

- Aos docentes do Depto. de Genética da ESALQ/USP, pelos ensinamentos recebidos.

- A minha querida familia, fonte de minha inspiração.

- A colega Moraima J. Garcia de Salcedo, por seu auxI lio na condução e anālise dos experimentos e por sua amizade fraternal.

- Ao amigo Itamar Soares de MeZo pelo auxilio prestado na revisão dos originais e por uma alegre convivência.

- Aos colegas Ailton Ribeiro, Carlos A. Labate, Cláudio H. Bruckner, Francisco Salcedo C., Marcy G.F. Torggler, Maria Lúcia C. Vieira, Mariana Zatarin e Satoru Yokoyama e demais colegas de curso, pelas su gestões, pelo estímulo e principalmente pela amizade sincera.

- Aos funcionários do Depto. de Genética da ESALQ/USP, especialmente à Erica Spruck, Gerda Spruck, Eisa A. A. Cesar, Terezinha J. Lodovico, Antonio Cella e Al cides Martins, por sua colaboração dedicada e atenciosa e pela sua amizade. 
- Ao Centro de Identificasão de Insetos Fitófagos, da Universidade Federal do Paraná, pela identificação dos afideos.

- A Fundaqão de Amparo à Pesquisa do Estado de São PauZo (FAPESP), pela concessão da bolsa de estudos.

o autor 
.iv.

I N D I C E

Página

RESUMO. . . . . . . . . . . . . . . . $v i$

SUMMARY . . . . . . . . . . . . . $\quad i x$

1. INTRODUÇÃO. . . • . . . . . . . . . . . . 1

2. REVISÃO DE LITERATURA . . . . . . . . . . . 4

2.1. Importância e ocorrência do WMV... . . . . 4

2.2. Sintomatologia . . . . . . . . . . 6

2.3. Caracterização e indexação do wMV. . . . . 7

2.4. Herança e ocorrência de resistência ao WMV em cucurbitáceas. . . . . . . . . 12

2.5. Tipos de resistềncia . . . . . . . 14

3. MAteriais E MÉtodos. ................ 17

3.1. Local de investigação. . . . . . . . . 17

3.2. Obtenção do Vỉrus do Mosaico da Melancia Raça $1($ WMV-1). . . . . . . . . . .

3.2.1. Coleta de isolados. . . . . . . 17

3.2.2. Identificação dos isolados . . . . 19

3.2.3. Teste de patogenicidade . . . . . 22

3.3. Preparo do inóculo e técnicas de inoculação 23

3.4. Critérios de avaliação. . . . . . . . 25

3.5. Fontes de resistência ao MWV-1 . . . . . 26

3.6. Reação de populações segregantes da cv. Piramoita ao wMV-1. . . . . . . . . 28

3.7. Reação de progênies de meios irmãos da cv. Piramoita ao WMV-1... . . . . . . . . 
4. RESUltados E discussão. . . . . • . . • . . . 36

4.1. Identificação dos isolados . . . . . . . 36

4.2. Teste de patogenicidade. . . . . . . . . 40

4.3. Fontes e tipos de resistência ao WMV-1 . • . 43

4.4. Reação de populações segregantes da cv: Pira moita ao WMV-1. . . . . . . . . . 49

4.5. Reação de progênies de meios-irmãos de abobrinha CV. Piramoita ao WMV-1.. . . . . . 54

5. CONCLUSÕES. • • • • • • • • • • • • • • • • 59

6. BIBLIOGRAFIA. • . . . . . . . . . . . . 61

7. APENDICE. • . . . . . . . . . . . . . 68 
.vi.

REACĀO DE ABOBRINHA (cucurbita moschata DUCHESNE)

AO VÍRUS DO MOSAICO DA MELANCIA RACA-1 (WMV-1)

AUTOR: Marcelo Yukio Kuabara

ORIENTADOR: Prof. Dr. Cyro Paulino.da Costa

RESUMO

Durante o processo de obtenção da abobrinha cv. Piramoita, não houve seleção direcionada à resistência ao Vírus do Mosaico da Melancia raça-l (WMV-1), de ocorrência endêmica nos campos de produção do Estado de São Paulo, pois esperou-se que o nivel de resistência do progenitor recorrente fosse recuperado atravēs do mētodo de retrocruzamento.

0 presente trabalho objetivou determinar e com parar níveis de resistência ao WMV-l em populações segregantés da cv. Piramoita; estimar alguns parâmetros genēticos para a reação de resistência, utilizando progênies de meios-ir mãos; identificar fontes e tipos de resistência dentro de C. moschata com potencial de utilização em programas de melhoramento.

Foram estudadas 39 populações de C. moschata, 


\section{.vii.}

incluindo cultivares e introduções; uma população de C. ecuadorensis, 14 populações segregantes de cv. Piramoita provenientes de 4 gerações de retrocruzamentos e 20 progênies de meios-irmãos de cada uma das populações $F_{6}, F_{7}, F_{8}, F_{9}$ e $F_{11}$ do quarto retrocruzamento. A avali ação da reação de resistência foi feita 4 semanas apōs a inoculação das plantas, uti lizando-se uma escala de notas de 1 a 5 , com base na severida de dos sintomas (sendo 1 ausência de sintomas e 5 deformação foliar). A reação de resistência foi expressa pelo nível médio de resistência (média ponderada) e pela porcentagem de plantas resistentes ( $p l a n t a s$ com notas 1 e 2 ).

As fontes de resistência de C. moschata mais promissoras foram a cv. Menina Brasileira - RS, a introdução Jerimum Vermelho, MA, e a cv. Tsurukubi com respectivamente $100 \%, 90,9 \%$ e $71,8 \%$ de plantas resistentes. A espécie C.ecua dorensis apresentou alto nivel de resistência $(100 \%$ plantas re sistentes), e mostrou-se ser resistente à multiplicação do ví rus, ao contrário da espécie C. moschata que mostrou resistência do tipo toleráncia,

0 método de retrocruzamento foi eficiente em recuperàr as caracteristicas do progenitor recorrente, bastan do quatro retrocruzamentos para recuperar um nivel de resistência equivalente ao da cv. Menina Brasileira. O progenitor recorrente apresentou $52,81 \%$ de plantas resistentes, enquan- 
viii.

to a média das populações do quarto retrocruzamento foi de $55,60 \%$ de plantas resistentes.

Os coeficientes de variação genética entre pro gênies foram baixos (entre $1,52 \%$ e $2,49 \%$ ) indicando pouca variabilidade genētica. As estimativas dos coeficientes de her dabilidade, no sentido restrito, também se mantiveram baixos (entre $6,91 \%$ e $19,10 \%$ ), indicando a necessidade de utilização de métodos de melhoramento mais precisos para a seleção visan do aumentar o nível de resistência na cr. Piramoita. 
.ix.

\title{
THE REACTION OF SUMMER SQUASH (cucurbita moschata DUCHESNE) TO THE WATERMELON MOSAIC VIRUS-1 (WMV-1)
}

\author{
AUTHOR: Marcelo Yukio Kuabara \\ ADVISER: Prof. Dr. Cyro Paulino da Costa
}

SUMMARY

During the obtaintion of the summer squash cv. Piramoita there was no selection for Watermelon Mosaic Virus 1 (WMV-1), a virus of endemic occurrence in the São Paulo State, because it was expected that the resistance level of the recurrent progenitor would be recovered by the backcross method.

This study aimed: to determine and to compare WMV-l resistance levels in segregating populations of. Piramoita; to estimate some of the genetic parameters of the resistance reaction. using half sib progenies; to identify sources and types of resistance in C. moschata.

39 populations of C. moschata, including cultivars and accessions, one accession of $C$. ecuadorensis, 
14 segregating populations of Piramoita obtained from four backcrosses generations and 20 half sib progenies of each one of the $F_{6}, F_{7}, F_{8}, F_{9}$ and $F_{11}$ populations of the 4 th backcross, were studied. The assesment of the resistance reaction was done 4 weeks after the inoculation of the plants, using a $1-5$ scale based on the severity of symptoms where, 1 was no sympton and 5 foliar deformation. The resistance reaction was expressed by the average resistance level (weighted mean) and by the percentage of resistant plants (plants rated. 1 and 2 ).

The most promissing sources of resistance in C. moschata were the cultivar Menina Brasileira-RS $(100 \%$ of resistant plants), the accession Jerimum Vermelho-MA $(90,9 \%$ of resistant plants) and the cultivar Tsurukubi $(71,8 \%$ of resistant plants). Tolerance was the type of resistance showed by $C$. moschata. The accession of $C$. ecuadorensis was highly resistant $(100 \%$ of resistant plants) and showed resistance to the virus multiplication.

The backcross method was efficient in recovering the characteristics of the recurrent progenitor. Four backcrosses were sufficient to recover the resistance level of cv. Menina Brasileira. The recurrent progenitor showed $52,81 \%$ of resistant plants and the average of the 4 th backcross populations was $55,60 \%$. 
. $x i$.

Coefficients of variation among progenies were low (between $1,52 \%$ and $2,49 \%$ ) indicating 1 ittle genetic variability. The estimated heritabilities (narrow sense) were also low (between $6,91 \%$ and $19,10 \%$ ), indicating the necessity of using more accurated breeding methods to increase the resistance level of the cv. Piramoita. 


\section{INTRODUGĀA}

A abobrinha e uma hortaliça na qual os frutos são consumidos imaturos, e representa uma das curcubitáceas de grande preferência e expressão econômica na règião Centro-sul do Brasil. A sua produção é baseada no cultivo de duas espécies de cucurbitāceas, representadas por Cucurbita moschata cv. Menina Brasileira e Cucurbita pepo cv. Caserta.

A C. pepo cv. Caserta tem häbito de crescimento tipo moita (gene braquitico) o que permite seu cultivo em espaçamento reduzido $(2 \times 1 \mathrm{~m})$. Um dos fatores limitantes déssa cultivar é a sua susceptibilidade a vārias doenças, entre as quais o Mosaico da Melancia raça l (WMV-1).

A C. moschata cv. Menina Brasileira é a preferida pelos agricultores porque apresenta resistência às principais doenças, inclusive ao WMV-1. Contudo, essa cultivar apresenta hábito de crescimento rasteiro, o que dificulta os 
tratos culturais e o manejo adequado da cultura.

o Mosaico da Melancia raça l (WMV-l) è uma virose de ocorrência endêmica e muitas vezes epidêmica nas àreas de cultivo do Estado de São Paulo. Sua ocorrência na cultura causa grandes prejuízos, pois mancha e deforma os fru tos. imaturos, afetando a qualidade e o aspecto visual do produto. Essa desqualificação do produto se dá quando ocorre uma infecção tardia, ou seja, antes do florescimento. Uma infecção em estādios iniciais da cultura, retarda o crescimento vegetativo, enfezando as plantas e reduzindo a sua capacidade produtiva.

No campo, sua disseminação é realizada princ í palmente por pulgões alados. Medidas de controle das princi pais viroses de cucurbitáceas têm sido feitas através do combate dos insetos vetores por inseticidas. No entanto, antes de morrerem, os pulgões são capazes de transmitir o vírus, somente com a introdução de seus estiletes na planta. Além do mais, os pulgões são polífagos e subsistem em hospedeiros que circundam a cultura. Assim sendo, a medida ideal de controle de viroses em cucurbitáceas só pode ser obtida através de cultivares geneticamente resistentes.

o Departamento de Genética, através do seu Setor de Melhoramento de Hortaliças, a partir de um cruzamento interespecifico (C. moschata $X C$. pepol e posteriores retro- 
cruzamentos (com C. moschata cv. Menina Brasileira), obteve a cultivar Piramoita, com hábito de crescimento tipo moita (ge ne braquiticol o que permite seu cultivo em linhas com espaça mento reduzido, como a cv. Caserta, numa população 10 vezes maior do que è normalmente usada na cv. Menina Brasileira. Teoricamente, durante esse processo de melhoramento, essa cultivar deve ter recuperado todas as características do seu progenitor recorrente, a cv. Menina Brasileira, com excessão do hábito decrescimento tipo moita. Durante essas värias etapas de retrocruzamento, não houve seleção direcionada à resistência ao WMV-1. Portanto,è de grande interesse, saber que nivel de resistência foi incorporada nas populações segregantes dessas diversas etapas, e caracterizar a potencialidade dessa cultivar, em solucionar o problema des se virus na cultura de Abobrinha.

o presente trabalho teve como objetivos:

1) Identificar fontes e tipos de resistência ao WMV-1.

2) Determinar e comparar niveis de resistência ao WMV-l em populações segregantes da abobrinha ć. Piramoita.

3) Estimar parâmetros genéticos nas populações segregantes, a partir de progênies de meios-irmãos. 
.4 .

\section{、2. REVISĀO DE LITERATURA}

2.1. IMPORTÂNCIA E OCORRÊNCIA DO WMV

- Virus do Mosaico da Melancia (Watermelon Mosaic Virus - WMV) é um dos vírus mais importantes que causam sintomas de mosaico em cucurbitáceas. Os danos econômicos causados pela sua incidência são consideráveis, principa mente quando a infecção ocorre na fase inicial do desenvolvimento da planta, reduzindo sua produtividade (Thomas, 1971 , citado por DEMSKI e CHALKLEY, 1972). Entretanto,o maior dano ocasionado pelo WMV, principalmente em culturas onde o fruto imaturo é o produto comercial, è a deformação que causa nesses frutos, tornando-os visualmente desqualificados para o mercado. DEMSKI e CHALKLEY (1972) observaram que, em abobrinha (Cucurbita pepo), onze ou mais dias apōs a infecção havia uma perda de $90 \%$ nos frutos comercializáveis, independentemen te do estádio de desenvolvimento da cultura por ocasião da infecção. 
o Virus do Mosaico da Melancia(WMV) encontra-se bastante disseminado em várias regiões de cultivo de cucurbi tāceas, sendo responsāvel por perdas significativas. No México foi relatado com incidência superior às demais viroses constatadas (NELSON et alii, 1966). Na Venezuela, a virose provocada por WMV foi a que mais prevaleceu, identificada em 85 das 95 amostras coletadas (LASTRA, 1968). MILNE et alii (1969), na Califörnia, constataram a presença de WMV em 287 das:365 amostras testadas. 0utros pesquisadores também rela tam o WMV como sendo, em geral, o virus prevalescente nas regiões sul e leste dos E.U.A. (ANDERSON, 1954; MCLEAN e MEYER, 1961 ; NELSON et a $i i i$,1962; WEBB et a $i i i$, 1965; SHANMUGASUNDARAM et alii, 1969). Tambēm na Costa Atlântica dos E.U.A., WEBB (1971) confirmou a presença do WMV em culturas de ábóbora, em 75 amostras das 87 coletadas. IGLESIAS e GONZALES citam outros países onde o WMV está presente. Alemanha Oriental, lugoslāvia, Romênia, Bulgāria, Hungria, Tchecoslováquia e Japão. EBRAHIM-NESBAT (1974) ainda cita ocorrências na Argentina, Égito, URSS, Nova Zelândia, India e Quênia. Existem ain da citações nas Antilhas Francesas (QUIOT et alii, 1971), El Salvador (FISCHNALER, 1972) e na Itālia (LOVISOLO e LISA,1983).

No Brasil, especificamente em São Paulo,o WMV é o virus mais comumente encontrado nas diversas áreas de cul tivo de cucurbitáceas (COSTA et alii, 1972). Também são en- 
contrados relatos de ocorrência em Brasilia, DF. (CUPERTINo et alii, 1974; LIN et alii, 1977); em Belém-PA (ALBUQUERQUE et.alii, 1972) e na região do Submédio São Francisco (ĀVILA et alii, 1984).

Outros dois grupos importantes de virus que causam mosaico em cucurbitäceas são o Vírus do Mosaico do Pepino (Cucumber Mosaic Virus - CMV) e o Virus do Mosaico da Abóbora (Squash Mosaic Virus - SqMV), que têm sido comumente relatados em diversas regiões de cultivo, juntamente com o WMV e outras viroses. Por ordem decrescente de incidência, o WMV aparece em primeiro lugar,seguido pelo CMV e pelo SqMV (NELSON et alii, 1966; LASTRA, 1968; MILNE et alii, 1969; COSTA et alii, 1972).

\subsection{Sintomatologia}

Os principais sintomas do WMV expressam-se pe la clorose e mosaico,principalmente nas folhas apicais. As fo lhas tornam-se distorcidas e curvadas. Ocorrem deformações das flores e posteriormente dos frutos, parecendo inibir o de senvolvimento normal destes (WHITAKER e DAVIS, 1962). Distorção foliar, raquitismo e mosaico nas partes vegetativas e nos. frutos são sintomas comuns em pepino, melão, melancia e abóbo ra (ZABALA e RAMALLO, 1968; PROVVIDENTI e SCHROEDER, 1970; QUIOT et alii, 1971; PURCIFULL e HIEBERT, 1979; ÁVILA,1982). Em melancia (Citrullus vulgaris, Schrad), a sin- 
tomatologia caracterizou-se por umá leve descoloração nos bor dos foliares. Poucas vezes observou-se mosaico intenso e enrugamento das folhas (ZABALA e RAMALLO, 1968). Já, PROVVIDENTI e SCHROEDER (1970), WEBB et a $i$ i (1965), PURCIFULL e HIEBERT (1979) relatam danos severos em melancia.

Nas abōboras do tipo moranga lCúcurbita māxima Duch.), os sintomas nas folhas manifestam-se na forma de mosaico, com cóloração verde päilido-amarelado entre as nervuras, alternados com cor verde normal. Em certas variedades observa-se grande deformação nas folhas. Os.frutos de moranga apresentam nodosidades sobre a epiderme e, são de tamanho reduzido quando a planta é infectada em estägio jovem. Nas abóboras (Cucurbita moschata Duch.) o mosaico torna as folhas crespas, com rugosidade; ocorre coloração verde escuro ao redor das nervuras com áreas intercalares de cor verde-ama relada. Nessas duas espécies de cucurbitáceas ocorre um raquitismo pronunciado e poucos frutos por planta (PROVVIDENTI e SCHROEDER, 1970).

\subsection{CaracteriząĀo e indeXąĀo do WMV}

Dentro do grupo do WMV existem três tipos conhecidos de virus, o WMV-1, o WMV-2 e- o WMV-M, sendo este último restrito, até o momento, no Marrocos (Lovisolo,1981, ci- 
.8 .

tado por AVILA et alii, 1984). O WMV-1 e o WMV-2 eram tidos como virus distintos (WEBB e SCOTT, 1965). Atualmente, sabe-se que são estirpes ou raças do mesmo virus, relacionadas serologicamente, com particulas semelhantes em tamanho e forma, graças aos trabalhos de MILNE e GROGAN (1969).

o Virus do Mosaico da Melanciarraça 1 (WMV-1), isoladamente, é capaz de infectar somente plantas da familia dàs cucurbitáceas, enquanto que a raça 2 afeta outras espécies além das cucurbitáceas (IGLESIAS e GONZALES, 1973; NELSON et alii, 1966; MILNE, GROGAN e KIMBLE, 1969;. MILNE e GROGAN, 1969). Os dois tipos não podem ser diferenciados nem entre si, nem entre os outros grupos de virus (SqMV, CMV e TRSV), apenas por observação visual dos hospedeiros atacados, visto que todos causam o mesmo tipo de sintoma (mosaico).

0s virus podem ser identificados por diversos mëtodos como por exemplo a serologia, a microscopia eletrônica e hospedeiros diferenciais. No entanto, nenhum método iso lado é perfeitamente seguro sendo mais aconselhável a utilização de mais de um.

No. caso de microscopia eletrônica o que se observa para WMV-1 e WMV-2 são partículas filamentosas (que variam de 690 a $900 \mathrm{~nm}$ de comprimento, com classe modal de $780 \mathrm{~nm}$ ) caracteristicas dós potivirus (PURCIFULL e HIEBERT, 1979).

No caso. de hospedeiros diferenciais, diferen- 
tes espécies de cucurbitāceas e não cucurbitāceas são inocula das com virus provenientes de hospedeiros infectados. Virus dis tintos provocam diferentes reações sintomatológicas nesses hospedeiros diferenciais, tornando possivel a sua identificação. E dificil obter-se um padrão comparativo de testes com hospe deiros diferenciais, pois nem todos os pesquisadores trabalham com as mesmas plantas testadoras. Entretanto, pode-se considerar, de maneira geral, a Tabela l como um resumo da observação de diversos pesquisadores, que executaram esse tipo de teste:

Uma outra observação importante na diferenciação desses grupos de vírus, è a maneira como são disseminados. A Tabela 2 apresenta um resumo das observações de diferentes autores.

A identificação do vírus pode ainda ser complementada com a determinação de suas propriedades físicas. Para o WMV, segundo o relato de vários autores, o ponto de inativação térmica ocorre entre $50^{\circ} \mathrm{C}$ a $60^{\circ} \mathrm{C}$ de temperatura numa exposição de 10 minutos. 0 ponto de diluição final ou ponto limite de diluição encontra-se entre $10^{-4}$ e $10^{-5}$ quan do se utilizá plantas de C. pepo (zABALA e RAMALLo, 1968; LAStra, 1968; MILNE e GROGAN, 1969; FISCHNALER, 1972).

A longevidade do vírus é influenciada pelo meio ambiente, sendo desfavorecida por temperaturas muito eleva- 
.10.

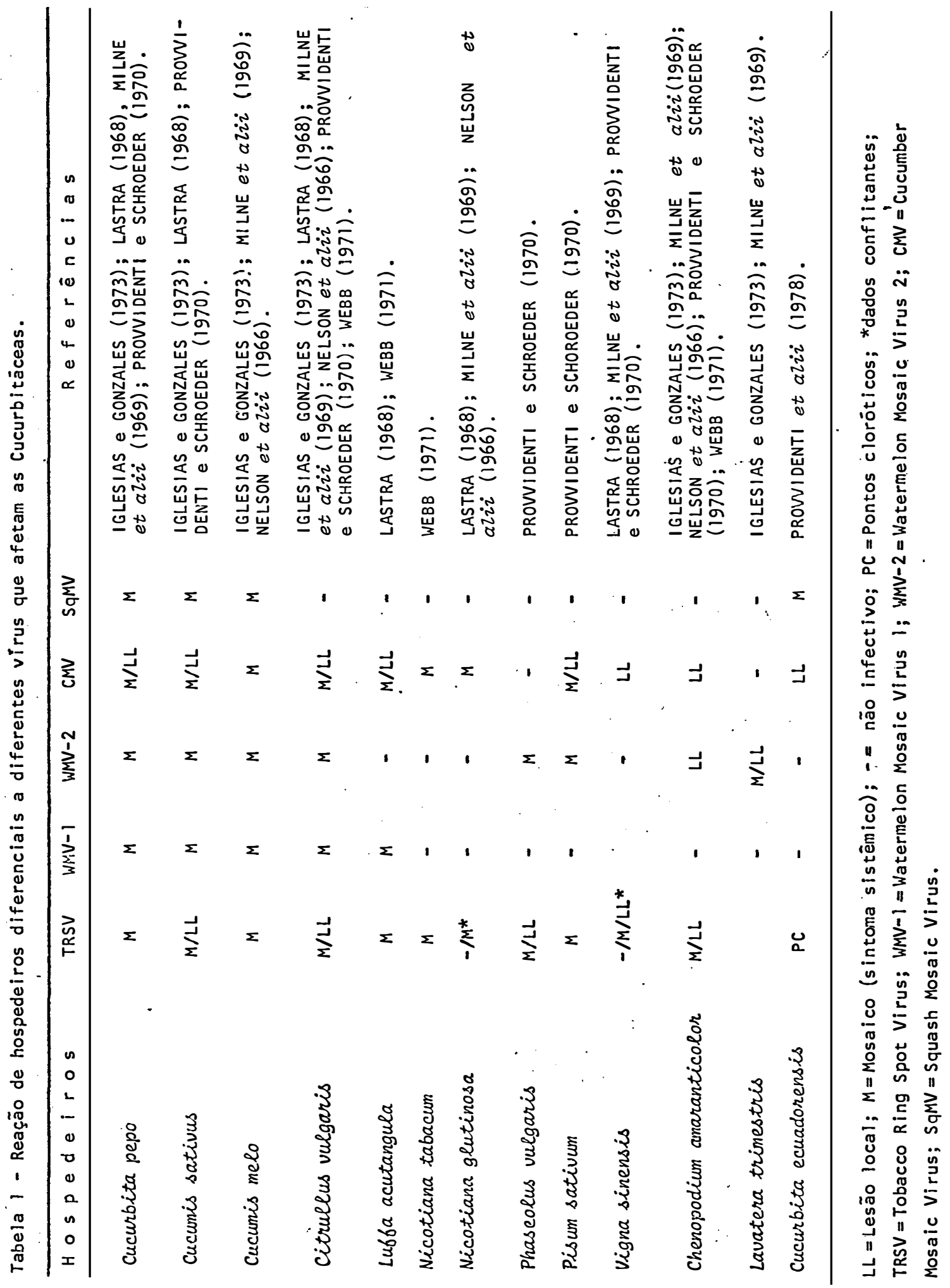


.11.

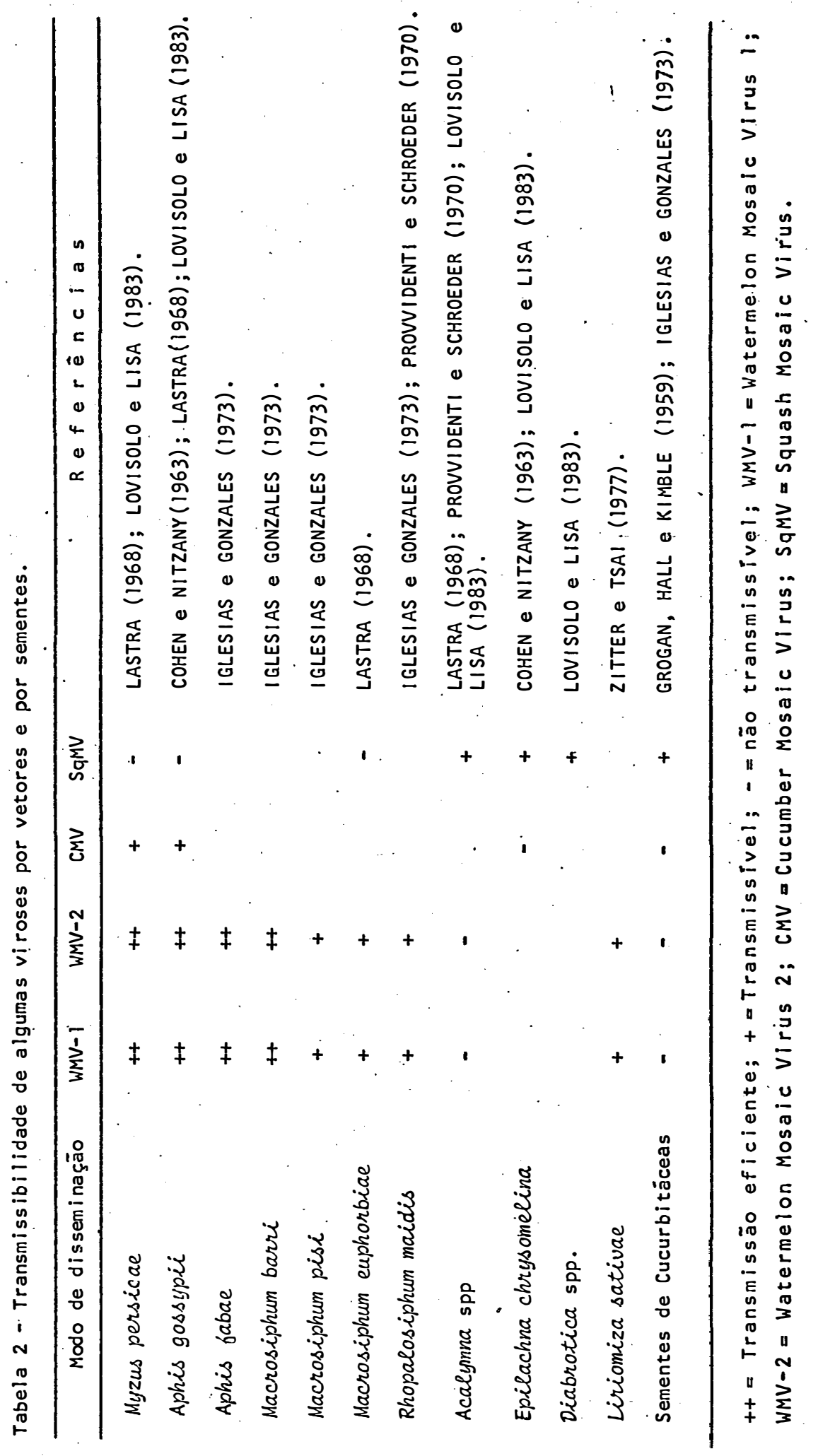


.12.

das. Segundo ZABALA e RAMALLO (1968) a longevidade pode ser positiva até 72 horas quando a temperatura varia entre $21^{\circ} \mathrm{C}$ e $25^{\circ} \mathrm{C}$. No entanto, a $18^{\circ} \mathrm{C}$ a longevidade foi de 16 a 32 dias.

\subsection{Herança e ocorrência de Resistência aO WMV em CUCUR- BITÁCEAS}

PROVVIDENT et alii (1978) testaram 14 espécies selvagens de Cucurbita quanto a reação às viroses mais comuns e destrutivas que afetavam as abóboras no estado de Nova York (E.U.A.). Dessas, Cucurbita ecuadorensis e Cucurbita foetidissima destacaram-se como as mais promissoras por serem resistentes ao CMV, WMV-1 e WMV-2, embora suscetiveis ao SqMV. 0 modo de herança e as relações de ligação da resís tência ao CMV entre as diversas espécies testadas variam bastante,assim como as relações de incompatibilidade com as espé cies cultivadas, dificultando a transferência de genes de resistência. No entanto, Wall e Whitaker (1971), citados por PROVVIDENT et alii (1978) demonstraram que C. ecuadorensis hi brida-se prontamente com C. maxima, o que foi confirmado por PROVVIDENTI èt alizi (1978) em cruzamentos recíprocos.

GREBER e HERRINGTON '(1980) assinalam que os hibridos entre C. ecuadorensis e C. maxima mostraram-se mais suscetíveis ao WMV-1 e WMV-2 em relação ao progenitor resís tente. No entanto, os sintomas foram moderados e ocorreram 
somente durante a fase inicial de crescimento. 0 material segregante apresentou um nivel de resistência adequado,indicando sua potencialidade para utilização em programas de retrocruzamento com C. maxima. As gerações $F_{1}$ e $F_{2}$ desse cruzamento ainda mostraram resistência à infecção sistêmica, quando inoculadas com CMV.

GARCIA S. (1984) avaliou 19 cultivares, introdu ções e híbridos de C. maxima para reação de resistência ao WMV-1. Destas, cinco destacaram-se como fontes de resistência promissoras. Estudando a herança de resistência ao WMV-1 em C. maxima, o autor verificou que ela è controlada pela ação de pelo menos dois genes recessivos, designados como $m$ e n. A manifestação do genótipo de resistência ocorre quando pelo menos um dos pares de genes está na forma recessiva. A ação gênica do carāter mostrou-se ser de natureza aditiva. MALUF et alii (1984), também trabalhando com abóbora moranga, mostraram que o caráter è controlado por um par de genes recessivo, também com ação gênica aditiva.

SILVA e COSTA (1975), avaliando a resistência ao WMV-I em cultivares de pepino (Cucumis sativas L.), observaram que a cultivar Formosa mostrou-se resistente a vários isolados desse vírus, bem como ao CMV. Cultivares americanas resistentes ao CMV, mostraram-se suscetiveis ao WMV-1. Os autores recomendam a cy. Formosa como fonte de resistência 
.14.

promissora para programas de melhoramento de pepino devido às suas características de valor comercial associadas com resís tência ao WMV-1. SILVA (1977) estudando o modo de herança nessa cultivar, demonstra que ela é devida a 3 pares de genes recessivos e com interação não alêlica. Na cv. Natsufushinari a resistência é devido a 3 pares de genes recessivos, mas não necessariamente alelos dos genes para resistência da cv. Formosa. No entanto, na cv. Aodai, com média de $8,75 \%$ de plantas resistentes, o controle genético é de natureza poligênica.

$$
\text { Em melão (Cucumis melo L.), WEBB (1978) obser- }
$$

vou que a resistência ao WMV-1, em materiais derivados da introdução ( $P$ I) 180280 , era controlada por um único gene dominante. Dados obtidos por. DELLA VECCHIA e ÂVILA (1984), que trabalharam com populações originárias do cruzamento da intro dução w6 e a cv. Amarelo, tambêm confirmam a herança condicio nada por um único gene dominante. No entanto, seus dados sur gerem dominância parcial ou ação de genes complementares ña resistência ao WMV-1 em melão.

\subsection{TIPOS DE RESISTÊNCIA}

o genōtipo das plantas tem um efeito significa tivo sobre a sua reação à infecção de um vírus específico. Assim, existem diversas situações a serem consideradas com res- 
peito à resistência oferecida por determinados hospedeiros. Tais situações ou reações são designadas por outros autores como tipos de resistência.

BAWDEN (1964) e SMITH (1974) classif́icaram as diferentes reações de resistência como imunidade, resistência à infecção, hipersensibilidade e tolerância.

Já RUSSEL (1978) fez uma classificação mais de talhada dos diferentes tipos de resistência, denominando-os de imunidade (as plantas não apresentam reação quando inocula das com o vírus), resistência à infecção (as plantas não são infectadas quando expostas à ação do vírus), resistência à dispersão (o vírus permanece localizado por uma reação de hipersensibilidade, com pouca ou nenhuma dispersão a partir do local de infecção), resistência a multiplicação (o vírus infecta a planta mas não se multiplica com a mesma intensidade que em plantas suscetiveis), tolerância (o virus multiplica-se e dispersa-se, mas o dano que produz é de pouco interesse eco nômico) e resistência a vetores (as plantas permanecem livres de vírus por resistirem a ação dos vetores).

Os tipos de resistência ao WMV que prevalecem nas espécies de Cucurbitáceas parecem ser de resistência a dispersão e do tipo tolerância. Assim, em melão, a introdução PI-180280 manifesta hipersensibilidade ao ser inocula da com WMV (WEBB e SCOTT, 1965). Por outro lado, em pepino, 
.16. as cultivares resistentes, Formosa, Natsufushinari, permitem a multiplicação do vírus, com ausência de sintomas nas folhas e frutos (SILVA, 1977). Tambēm em abóboras tipo moranga (Cucurbita maxima) a resistência è do tipo tolerância; jā a espècie Cucurbita ecuadorensis apresenta resistência à multiplicação. 
.17.

\section{MATERIAIS E MÉTODOS}

\subsection{LOCAL DE INVESTIGACĀO}

o presente trabalho foi conduzido sob condições de casa de vegetação e a nível de campo, nas instalações do Departamento de Genética - ESALQ/USP, localizadas na cidade de Piracicaba, SP., latitude $22^{\circ} 42^{\prime} 30^{\prime \prime}$.

As condições climăticas, reinantes durante a conclusão dos experimentos de campó são mostradas na figura 1 .

\subsection{Obtengāo do Vírus. do Mosaico da Melancia raga 1. (WMV-1) \\ 3.2.1. Coleta de isolados}

A partir de folhas ou frutos com sintomas de viroses de plantas de abóbora ou abobrinha,foram coletados 7 isolados em diferentes localidades do Estado de São Paulo. 


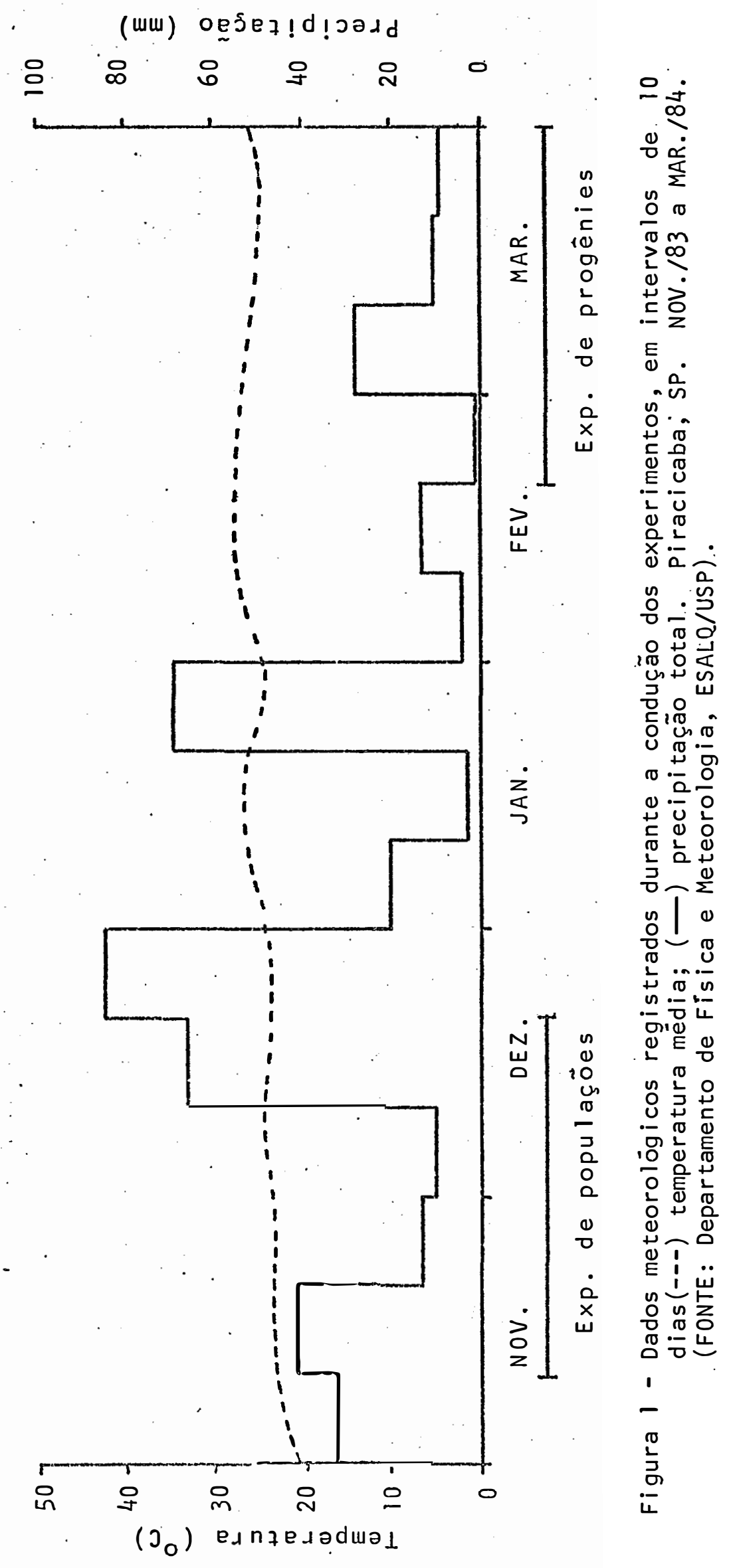


os isolados foram mantidos em plantas de Cucurbita pepo cv. Caserta, por sua reconhecida suscetibilidade a todos os virus que afetam as Cucurbitáceas. A Tabela 3 apresenta os diferentes isolados e sua procedência.

Tabela 3.- Relação dos isolados de vírụs causadores de mosa co em Cucurbitāceas e suas respectivas origens.

\begin{tabular}{|c|c|c|}
\hline I solado & Procedência & Hospedeiro \\
\hline$I S-I-E S A L Q$ & Piracicaba, SP. & Citrullus vulgaris \\
\hline Is-2 - ESALQ & Piracicaba, SP. & C. moschata cv. Piramoita \\
\hline Is-3 - ESALQ & Piracicaba, SP. & C. moschata cv. Piramoita \\
\hline $\mid s-1$ - Arujā & Arujā, SP: & C. moschata \\
\hline $1 s-1-\operatorname{Mog} i$ & Mogi das Cruzes, SP: & C. pepo cv. Caserta \\
\hline Is-2 - Mogi. & Mogi das Cruzes, SP. & C. pepo cv. Caserta \\
\hline $\mid s-1-A T$ & At ibaia, SP. & C. pepo cv. Caserta \\
\hline$I s-2-A T$ & Atibaia, SP. & C. pepo cv. Caserta \\
\hline
\end{tabular}

\subsubsection{IDENTIFICACĀO DOS ISOLADOS}

Para a identificação dos isolados utilizou-se o teste de hospedeiros diferenciais, auxiliado por um teste de transmissão por afídios. Como hospedeiros diferenciais foram selecionados as espécies que manifestavam sintomas distintos, a fim de se trabalhar com menor nümero de plantas. A Tabela 4 resume o résultados obtidos por diversos autores, os quais serviram como base para a identificação do Vírus do Mo- 
saico da Melancia raça $1($ WMV-l), dentre os isolados coletados para este estudo.

Tabela 4 - Reação de hospedeiros diferenciais utilizados na identificação do Vírus do Mosaico da Melancia raça 1 (WMV-1).

\begin{tabular}{|c|c|c|c|c|c|}
\hline Hos p e d e i ro & TRSV & WMV-1 & WMV-2 & CMV & SqWV \\
\hline Nicotiana tabacum & $M$ & - & - & M & - \\
\hline Chenopodium amaranticolor & $M / L L$. & - & LL & LL & - \\
\hline Phaseolus vulgaris cv. Black Turtle & $M / L L$ & - & M & - & - \\
\hline Citrullus vulgaris cv. Charleston. Gray & $M / L L$ & M & M & $M / L L$ & - \\
\hline Vigna sinensis & & - & - & $\mathrm{LL}$ & - \\
\hline Cucurbita pepo cv. Caserta & M & M & M & $M / L L$ & M \\
\hline Cucurbita ecuadorensis & PC & - & - & LL & $M$ \\
\hline
\end{tabular}

$L L=$ lesão local; $M=$ mosaico (sintoma sistêmico); $P C=$ pontos clorōticos; - não infectivo; TRSV = Tobacco Ring Spot Virus; WMV-1 = Watermelon Mosaic Virus 1; WMV-2 = Watermelon Mosaic Virus 2; CMV = Cucumber Mosaic Virus; SqMV = Squash Mosaic V rus.

Os ensaios de identificação dos isolados foram conduzidos em casa de vegetação, onde os hospedeiros diferenciais eram semeados em vasos de $20 \mathrm{~cm}$ de diâmetro,deixando-se 2 a 3 plantas por vaso. A inoculação dessas plantas foi fe ta na fase cotiledonar, exceto para Chenopodium amaranticolor e para Nicotiana tabacum, que foram inoculadas na quarta fo- 
lha verdadeira. Apōs a inoculação, as plantas eram avaliadas semanalmente, durante aproximadamente um mês, de modo que mesmo sintomas tardios poderiam ser observados.

Para o teste de transmissão por pulgões, foi utilizado somente o isolado ls-l Mogi,selecionado após o teste de patogenicidade para dar prosseguimento ao estudo. Para confirmar a identificação baseada na reação de Cucurbita ecua dorensis, que è o hospedeiro que separa o WMV-1 do SqMV, e pa ra verificar a transmissibilidade do isolado por vetores, importantíssima para uma eficiente disseminação natural nos experimentos de campo, foi realizado esse teste com pulgões.

Para o teste de transmissão foi utilizado pulgão da couve Aphidinae - Macrosiphini Brevicoryne brassicae (Linnē, 1798)*. Os pulgões foram mantịdos em plantas de couve antes da sua utilização ao ensaio, foram deixados em jejum por uma hora e meia, em placa de Petri. Após esse período, metade dos pulgões foram deixados sobre uma planta de C. pepo contendo o WMV-1, por 10 minutos, para a aquisição do vírus. Dez plantas de $C$. Pepo foram infestadas com pulgões isentos de vírus (tratamento testemunha), sendo colocados uma média de 20 pulgões adultos sobre a segunda folha verdadeira, com auxí

* Identificação realizada por LAZZZARI, S.M.N., Centro de Identificação de Insetos Fitófagos - Universidade Estadual do Paranā. 
lio de um pincel macio. Outras dez plantas foram infestadas da mesma forma, mas com pulgões que estavam se alimentando em planta portadora do vírus. A avaliação procedeu-se 20 dias apōs a infestação, sendo os resultados expressos em \% de plan tas com e sem sintomas da virose.

\subsubsection{Teste De PATOgEnicidade}

Apōs a identificação dos isolados, foram selecionados dois que apresentaram maior agressividade expressa pela.manifestação mais precoce dos sintomas. Diferentes espé cies de Cucurbitäceas foram inoculadas com esses 2 isolados, com o propósito de se escolhèr aquele que induzisse os sintomas de mosaico em primeiro lugar, de modo a ser utilizado para discriminação precoce do material resistente e suscetível. Para este ensaio foram utilizados as seguintes espécies:

C. pepo var. melopepo cv. Caserta

C. pepo var. ovibera

C. pepo cv. Marvella

C. pepo cv. White Bush

C. maxima cv. Moranga Coroa (BGH-947)

C. maxima cv. Moranga Exposição

C. maxima cv. Zapallo de Tronco

C. moschata cv. Menina Brasileira

C. moschata cv. Abóbora Seca

C. ecuadorensis 


\subsection{Preparo do inóculo e técnicas de inoculagèo}

0 isolado mais agressivo (ls-l Mogi), escolhido com base no teste de patogenicidade, foi mantido em plantas de C. pepo cv. Caserta, que também foi utilizada como padrão de suscetibilidade em todos os experimentos.

o inōculo do vírus foi preparado macerando-se

folhas jovens de C. pepo, com sintomas severos de mosaico, numa solução tampão de fosfato (Solução de Gomori) $0,1 \mathrm{M}$ e pH 7,0: A diluição do inōculo seguiu a proporção de $1 \mathrm{~g}$ (peso frescol de folhas com sintomas para $10 \mathrm{ml}$ da solução tampão. Para se obter essa solução tampão, foram preparadas 2 soluções estoques: a primeira com fosfato de: södio monobásico $\left(\mathrm{NaH}_{2} \mathrm{PO}_{4}\right)$ a $13,8 \mathrm{~g} / 1$ e a segunda com fosfato de sōdio dibásico $\left(\mathrm{Na}_{2} \mathrm{HPO}_{4}\right)$ a $14,2 \mathrm{~g} / 1$. Misturando-se as duas soluções esto , ques na proporção $1 \mathrm{NaH}_{2} \mathrm{PO}_{4}: 2 \mathrm{Na}_{2} \mathrm{HPO}_{4}$, obtēm-se uma solução tampão com pH aproximadamente 7,0. Alèm disso, também è adicionado um redutor, o Bissulfito de sódio ( $\left.\mathrm{NaHSO}_{3}\right)$, na base de $0,19 \mathrm{~g} / 100 \mathrm{ml}$ de solução.

Inicialmente, para os experimentos conduzidos. em casa de vegetação, as inoculações seguiram o método tradicional: a solução contendo o vírus era esfregado sobre os cotilèdones das plantas previamente polvilhadas com Carborundum (abrasivo). Embora bastante efetivo, o método exige muita mão-de-obra quando se deseja triabalhar com um elevado nü- 
mero de plantas. Assim, com base em relatos de Takahashi (1947) e Yarwood (1952), citados por SMITH (1960), que conseguiram com o uso de um pincel duro, um mētodo adequado para a transmissão de algumas viroses em plantas de folhas pilosas, testou-se a escova de dentes como método de inoculação alternativo. Em testes comparativos utilizando plantas de C. pepo cv. Caserta; não houve diferença entre os dois métodos empregados; $100 \%$ das plantas testadas mostraram sintomas de mosaico e deformação a partir da quarta ou quinta folha verdadeira.

A tēcnica com escova de dentes (com cerdas de dureza médial consiste em se esfregá-la suavemente sobre os cotilēdones, mergulhando-a previamente na solução viral. As cerdas substituem o efeito causado pelo abrasivo,eliminando a operação de se espalhā-lo. Alēm disso, não se mẹergulha a escova tantas vezes quanto é necessārio mergulhar os dedos, o que conserva a solução viral limpa por maior tempo alēm de tornar mais rápida a inoculação das plantas.

Para se observar a eficiência da inoculação na tural no campo, realizada por insetos vetores, foram deixadas, dentro de cada parcela, plantas. inoculadas somente com a solução tampão. A grande maioria dessas plantas testemunhas apresentaram-se com sintomas por ocasião de avaliação, demon $\underline{s}$ trando a efetividade da inoculação natural. Alēm disso, foram intercaladas parcelas de C. pepo cv. Caserta (padrão de 
suscetibilidade) inoculadas com o virus,que serviram como fon te de inóculo para disseminação natural, garantindo assim, através dos vetores, a māxima inoculação do WMV-l no campo.

\subsection{CRIT'́rios de AVALiAcāo}

A avaliação da reação de C. moschata ao WMV-l foi efetuada aproximadamente 30 dias apōs a inoculação (aproximadamente 40 dias da semeadura). Resultados de ensaios pre liminares permitiram constatar que o material poderia ser dís criminado satisfatoriamente durante esse período. Avaliações posteriores a essa data mostraram poucas alterações nos resul tados. Além disso, com 4 semanas apōs a inoculação, a teste munha padrão de suscetibilidade, a. C. pepo cv. Caserta, apresentava $100 \%$ de plantas com sintomas de mosaico e deformação nas folhas.

As avaliações foram realizadas utilizando-se uma escala de notas de 1 a 5 com base nạ severidade dos sinto mas conforme o quadro abaixo.

\begin{tabular}{ll}
\hline Nota & S i n t o m a s \\
\hline 1 & Ausência de sintomas. \\
2 & Sintomas leves de mosaico. \\
3 & Sintomas fortes de mosaico a partir da loa folha. \\
4 & Sintomas fortes de mosaico até a loa folha. \\
5 & Deformaçãofoliar. \\
\hline
\end{tabular}


A reação de resistência ao WMV-1 foi expressa em termos de nível médio de resistência, como indicado por SILVA (1977), e também pela porcentagem de plantas resistentes, onde plantas com ausência de sintomas ou mostrando mosa co leve, nas folhas (notas 1 e 2) foram consideradas com resistentes.

O nivel médio de resistência (média ponderada) foi calculado segundo a fórmula abaixo (SILVA, 1977):

$$
\bar{x}=\frac{\left(x_{1} \cdot 1\right)+\left(x_{2} \cdot 2\right)+\left(x_{3} \cdot 3\right)+\left(x_{4} \cdot 4\right)+\left(x_{5} \cdot 5\right)}{n}
$$

onde:

$$
\begin{aligned}
& \bar{x}=\text { nível médio de resistência; } \\
& x_{1} \text { a } x_{5}=\begin{array}{l}
\text { número de plantas classificadas } \\
\text { com notas } 1 \text { a } 5 \text {, respectivamente; }
\end{array} \\
& n=\text { número total de plantas avaliadas. }
\end{aligned}
$$

\subsection{FonTES DE RESISTÊNCIA AO WMV-1}

Para a seleção de fontes de resistência ao WMV- 1 foram avaliadas trinta e nove introduções e cultivares de C. moschata além de uma introdução de $C$. ecuadorensis per- tencentes à coleção do Setor de Melhoramento de Hortaliças, do Instituto de Génética, ESALQ/USP. O material testado assim como sua procedência ou origem, consta na Tabela 5 . 
Tabela 5 - Denơninação e procedência das introduções e/ou cultivares de C. moscha ta e C. ecuadorersis avaliados quanto à reação de resistência ao WMV- 1 . Piracicaba, SP., 1984.

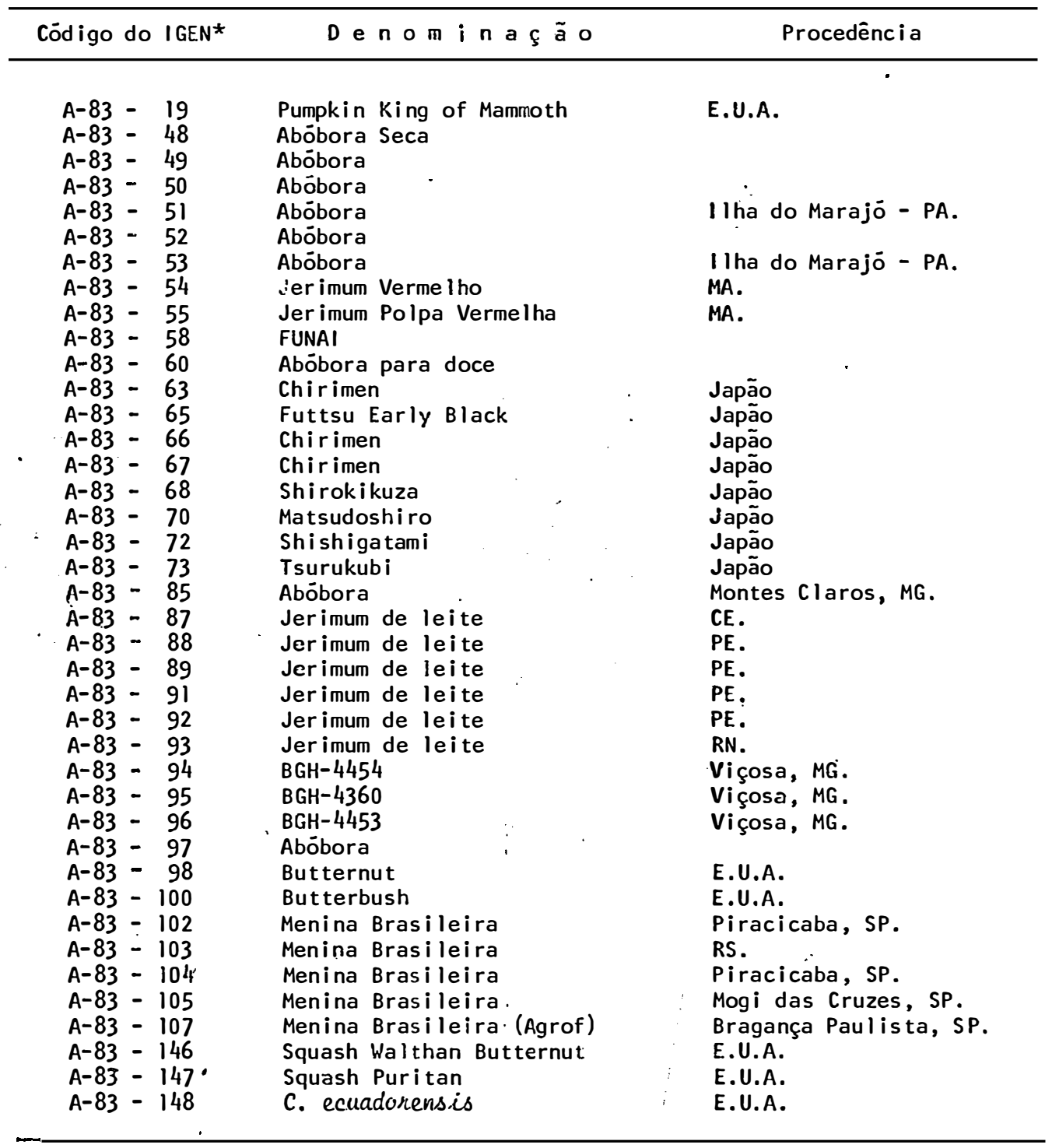

*Código da coleção de Cucurbitäceas pertencentes ao Setor de Melhoramento de Hortaliças do Instituto de Genētica, ESALQ/USP. 
0 material foi avaliado em dois experimentos, conduzidos em casa de vegetação. No primeiro discriminou-se o material suscetivel, de modo que no 2 e experimento, foram testados somente aqueles materiais potencialmente resistentes, com maior nūmero de plantas, a fim de se confirmar ou não, 1 o seu valor como fonte de resistência.

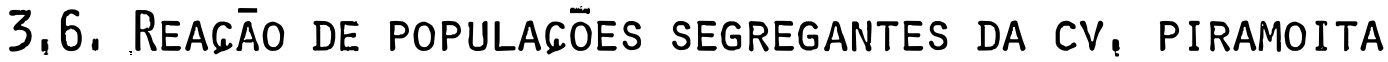 AO WMV-1}

0 melhoramento de abobrinha com häbito de cres cimento tipo moita, que resultou na obtenção da cv. Piramoita foi iniciado no Setor de Melhoramento de Hortaliças por volta de 1973. A partir de uma população $F_{2}$,proveniente do cruzamento interespecifico $C$. pepo cv. Yankee Hybrid(moita) X C. moschata cv. Butternut (rasteiro) inicioúse um programa de 4 retrocruzamentos, utilizando-se como progenitor recorrente à C. moschata cv. Menina Brasileira (rasteiro). Nestas populações ocorreram segregações para caracteres de formato, cor e tamanho de fruto, maturidade,prolificidade e reação às doenças, porēm jā apresentando o caráter braquítico. Durante os ciclos de seleção que se sucederam, não houve seleção dire cionada à resistência ao WMV-l. Sendo o progenitor recorrente resistente ao WMV-l e tendo em vista o método de melhoramento utilizado, a cv. Piramoita deveria ter recuperado um nI 
vel de resistência pelo menos equivalente ao da cv. Menina Brasileira. Para se comprovar esta hipótese, foi instalado um experimento para testar a reação das seguintes populações segregantes da cv. Piramoita:

$-F_{1} R C_{1}, F_{2} R C_{1}$.

$-F_{2} R C_{2}, F_{2} R C_{2}, F_{3} R C_{2}, F_{4} R C_{2}$.

$-F_{1} R C_{3}, F_{2} R C_{3}$.

$-\mathrm{F}_{2} \mathrm{RC}_{4}, \mathrm{~F}_{2} \mathrm{RC}_{4}, \mathrm{~F}_{3} \mathrm{RC}_{4}, \mathrm{~F}_{4} \mathrm{RC}_{4}, \mathrm{~F}_{5} \mathrm{RC}_{4}, \mathrm{~F}_{6} \mathrm{RC}_{4}$.

Das 3 populações disponíveis da cv. Menina Brä sileira, a população C2 foi utilizado com padrão de comparação. As populações eram denominadas ciclo zero (co), ciclo l (C1) e ciclo 2 ( $(C 2)$, porque sofreram seleção massal para resistência a.o WMV-l em condições de inoculação natural. Portanto, como testemunha foi escolhida a população de ciclo mais avançado.

0 experimento foi conduzido em condições de campo, plantando-se 10 sementes por metro linear e com espaçamento de 2 metros entre linhas. Utilizou-se o delineamento em blocos casualizados, com 2 repetições, cada parcela contendo 15 metros de linha. Separando cada parcela, uma bordadura com 10 plantas de C. pepo cv. Caserta, para verificar a uniformidade de inoculação e também como fonte de inóculo para a disseminação natural. Para verificar a eficiência da ação dos vetores, foram deixadas, a cada 2 metros de linha, 
uma planta inoculada com solução tampão sem vírus. Dependendo da proporção dessas plantas, com ou sem sintomas de vírus, na fase de avaliação,pode-se ter uma noção da efetividade da inoculação natural. A disseminação natural é importante nesse tipo de experimento,pois diminui o nümero de plantas que possam ter escapado à inoculação artificial.

0s resultados das avaliações foram apresentados em porcentagem de plantas resistentes e também pelo nivel médio de resistência. Os dados foram analisados estatisticamente segundo o teste $X^{2}$ (qui-quadrado); segundo PIMENTEL GoMES (1981), comparando as populações, duas a duas, utilizando tabelas de contingência $2 \times 2$.

\subsection{REAGĀO DE PROGÊNIES DE MEIOS IRMĀOS DA CV, PIRAMOITA AO WMV-1}

Para o estudo quantitativo da reação de resistência ao WMV-l foram avaliadas 20 progênies de meios-irmãos de cada uma das seguintes populações: $F_{6} R C_{4}, F_{7} R C_{4}, F_{8} R C_{4}$, $\mathrm{F}_{9} \mathrm{RC}_{4}, \mathrm{~F}_{11} \mathrm{RC}_{4}$, (tambēm foram testadas 20 progênies da população $\mathrm{F}_{10} \mathrm{RC}_{4}$. No entanto, como a maioria das progênies da população $\mathrm{F}_{10} \mathrm{RC}_{4}$ apresentou um "stand" de plantas muito baixo, esita população foi eliminada das anālises).

0 experimento foi conduzido em condições de 
campo seguindo o delineamento de blocos casualizados, com 3 repetições, tendo cada parcela 2 metros de linha. A cada me-, tro linear foram semeadas 10 sementes, e o espaçamento entre linhas foi de $2 \mathrm{~m}$.

Nas anālises de variância foram utilizados os dados de nível médió de resistência,transformados em $\sqrt{x+0,5}$, segundo o procedimento de SNEDECOR e COCHRAN (1973). As anälises de variancias foram realizadas com médias de parcelas, segundo metodologia de STEEL e TORRIE (1960). Para a estimação dos parâmetros genéticos,empregou-se o seguinte modelo ma temātico utilizado por GERALDI (1977), PAIVA(1980) e por GARCIA S. (1984):

$$
Y_{i j k l}=\mu+P_{i}+r_{j}+b_{j k}+e_{i j k}+d_{i j k l}
$$

onde:

$$
\begin{aligned}
& Y_{i j k l} \text { : observação no indivíduo } 1 \text {, da progênie } \\
& i \text {, no blocok, dentro da repetição j; } \\
& \mu \text { " } \quad \text { média geral; } \\
& P_{i}: \begin{array}{l}
\text { : eféito aleatório do tratamento } \quad(i=1, \\
2, \ldots, s) ;
\end{array}
\end{aligned}
$$

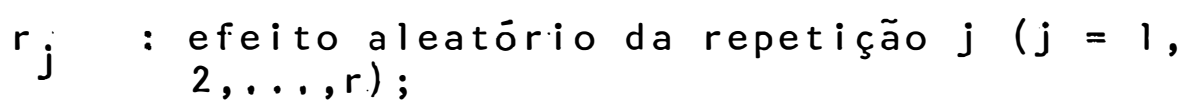

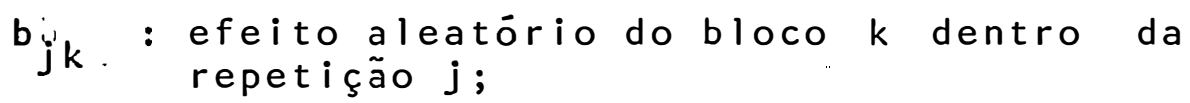

$$
\begin{aligned}
& \begin{aligned}
e_{i j k}: & \text { efeito aleatório relativo ao erro intra } \\
& \text { bloco ijk; }
\end{aligned}
\end{aligned}
$$



$d_{i j k l}$ : efeito aleatório relativo ao erro den- tro da parcela ijk, associado ao indi- víduo $1(1,2, \ldots, n)$.

Considerando-se o modelo utilizado como sendo aleatório, isto é, com excessão da média, todps os efeitos são considerados aleatörios, temos as seguintes esperanças ma temäticas (E):

$$
\begin{aligned}
& E\left(P_{i}\right)=E\left(r_{j}\right)=E\left(b_{i j k}\right)=E\left(e_{i j k}\right)=E\left(d_{i j k l}\right)=0 \\
& E\left(p_{i}^{2}\right)=\sigma_{p}^{2} ; E\left(r_{j}^{2}\right)=\sigma_{r}^{2} ; E\left(\sigma_{i j k}^{2}\right)=\sigma_{e}^{2} ; E\left(d_{i j k l}^{2}\right)=\sigma_{d}^{2} ;
\end{aligned}
$$

sendo:

$\sigma_{p}^{2}$ : variância genētica entre progênies;

$\sigma_{r}^{2}$ : variância ambiental entre populações;

$\sigma_{e}^{2}$ : variância do erro ambiental intra blocos;

$\sigma_{d}^{2}$ : variância fenotípica entre plantas dentro de progênies;

Os quadrados médios dentro de progênies $\left(\overline{Q M}_{d}\right)$ foram obtidos independentemente, atravēs das médias das estimativas das variâncias individuais dentro de parcelas, ponderadas pelos graus de liberdade, ou seja:

$$
\overline{Q M}_{d}=\frac{\sum_{i j}(g l)_{i j}\left(Q M_{d}\right)^{\circ} i j}{\sum_{i j}(g l)_{i j}}=\frac{\sum_{i j}\left(S Q_{d}\right)_{i j}}{\sum_{i j}(g l)_{i j}}
$$


sendo:

$$
\begin{aligned}
& \overline{Q M}_{d}: \text { quadrado médio dentro de cada parcela; } \\
& S Q_{d} \text { : soma de quadrados dentro de cada parcela; } \\
& \text { gl : número de graus de liberdade dentro de } \\
& \text { cada parcela. }
\end{aligned}
$$

Por outro lado, devido à existência de um núme ro variável de plantas por parcela, o valor de "K" foi calculado com base na média harmônica, expressa na seguinte fórmula:

$$
\frac{1}{\bar{k}}=\frac{1}{r \cdot n}\left(\frac{1}{K_{1}}+\frac{1}{k_{2}}+\ldots \frac{1}{k_{n}}\right)
$$

onde:

$\bar{k}$ : média harmônica do número de plantas por parcela;

$r$ : nümero de repetições;

n : nümero de progênies;

$K_{i}$ : número de plantas em cada parcela.

Na Tabela 6 são apresentadas as esperanças dos quadrados médios, ao nivel de progênie e ao nivel de plan tas. Seguindo-se a metodologia apresentada por VENCOVSKY (1969), as estimativas da variância genética entre progênies $\left(\hat{\sigma}_{p}^{2}\right)$, da variância do erro ambiental entre parcelas $\left(\hat{\sigma}_{\mathrm{e}}^{2}\right)$ e da variância fenotípica dentro de progênies $\left(\hat{\sigma}_{p}^{2}\right)$, foram obtidas 
ao nivel de plantas, para cada caráter, separadamente, a partir dos quadrados médios, conforme representação a seguir:

$$
\begin{aligned}
& \hat{\sigma}_{d}^{2}=Q_{3} \\
& \hat{\sigma}_{e}^{2}=\left(Q-\frac{Q_{3}}{n}\right) \\
& \hat{\sigma}_{p}^{2}=\left(Q_{1}-Q_{2}\right) / r
\end{aligned}
$$

Continuando com a mesma metodologia, as estima tivas da variancia genética aditiva $\left(\hat{\sigma}_{A}^{2}\right)$, da variância fenotí pica entre plantas $\left(\hat{\sigma}_{F}^{2}\right)$, da variancia fenotípica entre médias de progênies ( $\left.\hat{\sigma} \frac{2}{F}\right)$ e dos coeficientes de herdabilidade no sentido restrito, ao nivel de médias de parcela $\left(\hbar^{2}\right)$, foram abtidos da seguinte maneira:

$$
\begin{aligned}
& \hat{\sigma}_{A}^{2}=4 \hat{\sigma}_{\mathrm{P}}^{2} \\
& \sigma_{\mathrm{F}}^{2}=\sigma_{\mathrm{P}}^{2}+\sigma_{\mathrm{e}}^{2}+\sigma_{\mathrm{d}}^{2} \\
& \sigma_{\mathrm{F}}^{2}=\sigma_{\mathrm{P}}^{2}+\sigma_{\mathrm{e}}^{2} / r+\sigma_{\mathrm{d}}^{2} / \mathrm{nr}=\grave{Q}_{1} / \mathrm{nr} \\
& \hat{h}^{2}=\sigma_{\mathrm{A}}^{2} / \sigma_{\mathrm{F}}^{2}
\end{aligned}
$$

0 coeficiente de variação genética (c.v.gen.\%) para cada população foi calculado da seguinte forma:

$$
\text { cv gen } \%=\frac{\sqrt{\sigma_{p}^{2}}}{\bar{x}} \times 100
$$

onde:

$$
\bar{X} \text { = mēdia da reação de resistência da população. }
$$




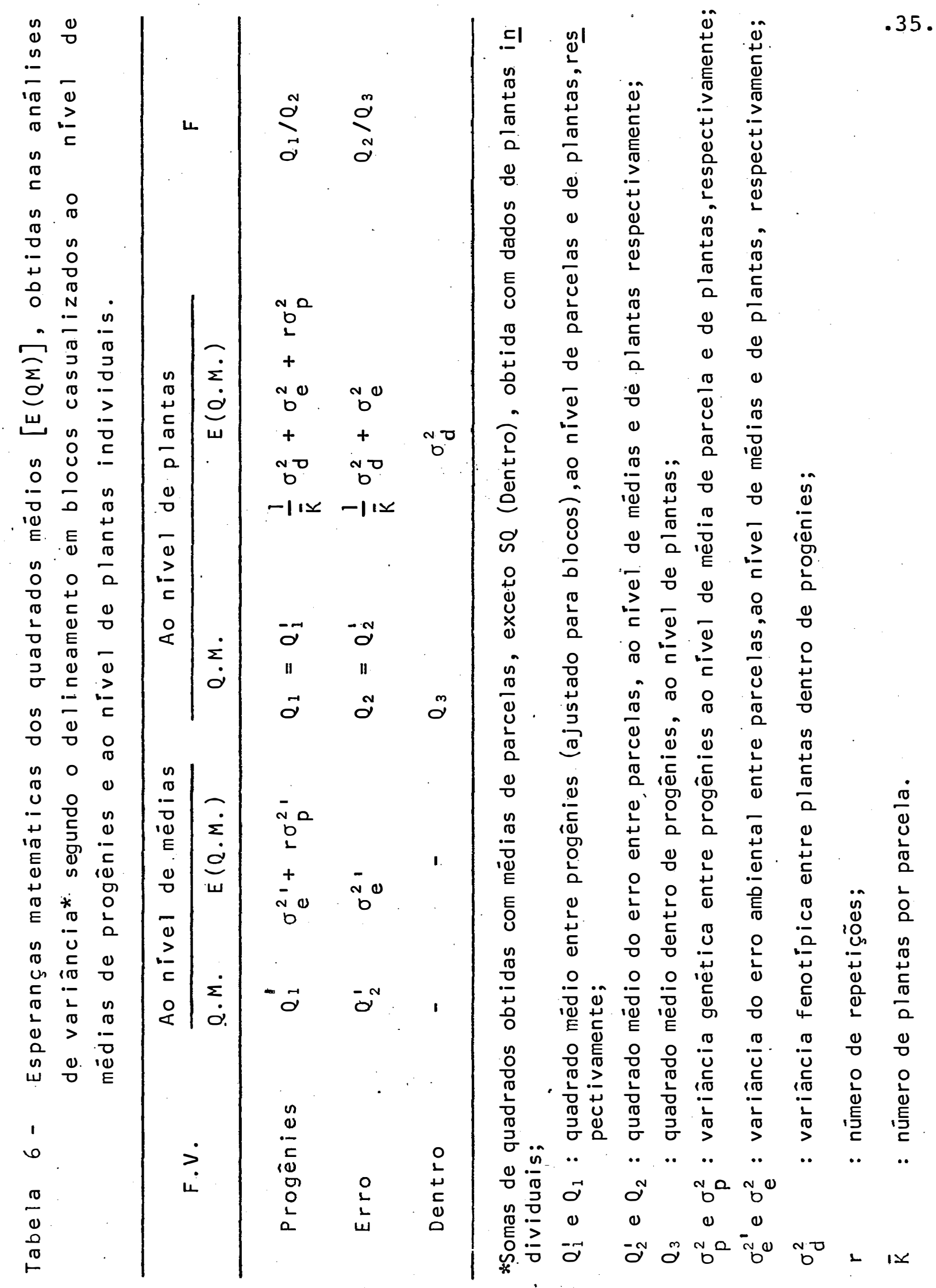




\section{RESULTADOS E DISCUSSAO}

\subsection{IDENTIFICACĀOO DOS ISOLADOS}

A reação dos hospedeiros diferenciais aos 8 isolados coletados é mostrada na Tabela 7.

Os isolados is-1 e Is-2 ESALQ foram identificados como sendo WMV-1; o segundo, embora um pouco mais agres sivo que o primeiro, não induzia a formação de sintomas seve ros o suficiente para que pudesse ser utilizado nos experimen tos. Além disso, após sucessivas passagens em melancia ( $\mathrm{C} i$ trullus vulgaris), esses isolados tornaram-se, aparentemente, menos agressivos. Tal fato pode ter ocorrido pela presença de substâncias inibidoras ou mesmo uma diminuição na concentração das partículas de vírus. Por essa razão, passou-se en tão a utilizar a C. pepo cv. Caserta como hospedeiro, pois è reconhecida como espécie altamente suscetivel e que não apresenta inibidores. Entretanto, jä na fase final dos experimen 
.37

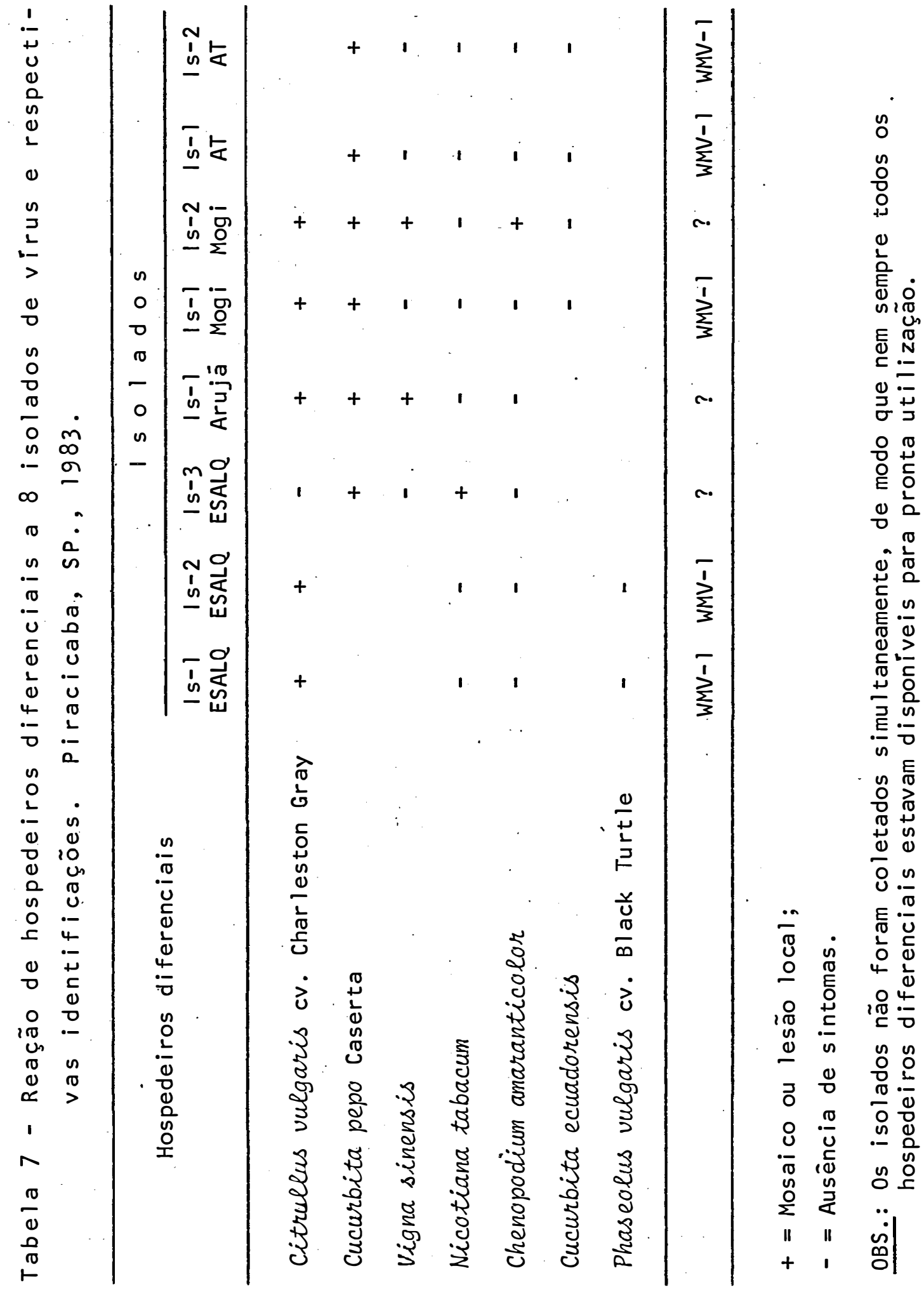


tos notou-se um processo inverso: as passagens sucessivas em plantas de C. pepo pareceram aumentar a agressividade do isolado. Para minimizar esse problema poderia ser tentado uma redução na concentração do inōculo. Supõe-se que com essa redução, os sintomas tenderiam a se manifestar mais tardiamen te. Ainda assim, os métodos de inoculação artificial como o utilizado são bastante drāsticos e não simulam o que ocorre na natureza. Tanto que alguns pesquisadores (comunicação pes soal), que trabalham com melhoramento para resistância a viro ses de cucurbitāceas procuram utilizar a disseminação natural, sempre que possivel. Entretanto, tal procedimento,apesar de sua praticidade, não impede a entrada de vetores provenientes de outras āreas, que podem estar portando outros vírus.

Uma outra hipótese seria a utilização de um hospedeiro selvagem, que não è nem completamente resistente, nem completamente suscetível. Sugere-se a utilização do meIão de São Caetano (Momordica charantia) como hospedeiro. E uma planta daninha frequentemente encontrada sobre cercas e já foi relatado por ADLERZ (1972) como hospedeira do WMV- 1 . Esta também pode ser utilizada como fonte natural de inóculo,. pois esse mesmo autor relatou que, somente as plantações de abobrinha situadas próximas de concentrações de M. charantia, mostravam-se atacadas pelo WMV-1.

Todos os isolados que não foram identificados 
como sendo WMV-1 (Is-3 ESALQ, Is-1 Arujä e Is-2 Mogi) foram prontamente eliminados para evitar contaminação.

Os dois isolados coletados em Atibaia foram identificados como sendo WMV-1. No entanto, por ser mais agressivo,somente o Is-2 AT foi escolhido paraser testado, juntamente com o Is-l Mogi, segundo sua patogenicidade. Com base nos resultados desse teste de patogenicidade ( $v i d e$ item 4.2.), o isolado de WMV-l escolhido para dar continuidade ao estudo foi o Is-l Mogi. Posteriormente, esse isolado foi tes tado segundo sua transmissibilidade por vetores, fator importante na disseminação natural no campo e também para ratificar a sua identificação como WMV-l.

0 teste de transmissão por pulgões mostrou que $100 \%$ das plantas infectadas com pulgões viruliferos apresentaram os sintomas típicos da virose e $100 \%$ das plantas infestadas com pulgões isentos do vírus apresentaram-se sadias. Como o SqMV não se transmite por pulgões e sim por algumas espēcies de coleópteros (COHEN e NITZANI, 1.963; LASTRA, 1968; LOVISOLO e LISA, 1983; PROVVIDENT e SCHOEDER, 1970), descartou-se a possibilidade do isolado pertencer a esse grupo, confirmando os resultados obtidos, através dos hospedeiros diferenciais. A transmissibilidade por vetores é importante pelo fato de que a disseminação do WMV-l é realizada por pulgões (COHEN e NITZANI, 1963; IGLESIAS e GONZALEZ, 1973; LASTRA, 1968; LOVI- 
.40 .

SOLO e LISA, 1983). Nos ensaios a nivel de campo, essa disseminação por vetores auxiliou na diminuição do nūmero de plan tas que pudessem estar isentas de virus em função de escapes na inoculação mecânica.

Como se observa na Tabela 7 , o virus predominante nos isolados coletados foi o Vírus do Mosaico da melancia raça 1 (WMV-1). Não foi objetivo deste trabalho realiżar um levantamento das viroses nas regiões produtoras do Estado. No entanto, mesmo os resultados obtidos com essa coleta restrita as poucas regiões, concordam com cosTA et alii (1972) e SILVA (1977) que relataram a predominância do WMV-l nas regiões produtoras do Estado de São Paulo. MILNE et alii (1969) e PROVVIDENT e SCHROEDER (1970) afirmam que a predominância do WMV-l numa região agrícola vai depender principalmente da presença de espécies de Cucurbitāceas, que constituem hospedeiros restritos do WMV-1.

\subsection{Teste DE Patogenicidade}

A reação de diferentes espécies de Cucurbitā ceas com relação à patogenicidade dos dois isolados de WMV-l escolhidos, é mostrada na Tabela 8 .

C.omo pode-se observar, dentro das espécies mais resistentes não houve grandes diferenças de reações aos dois 


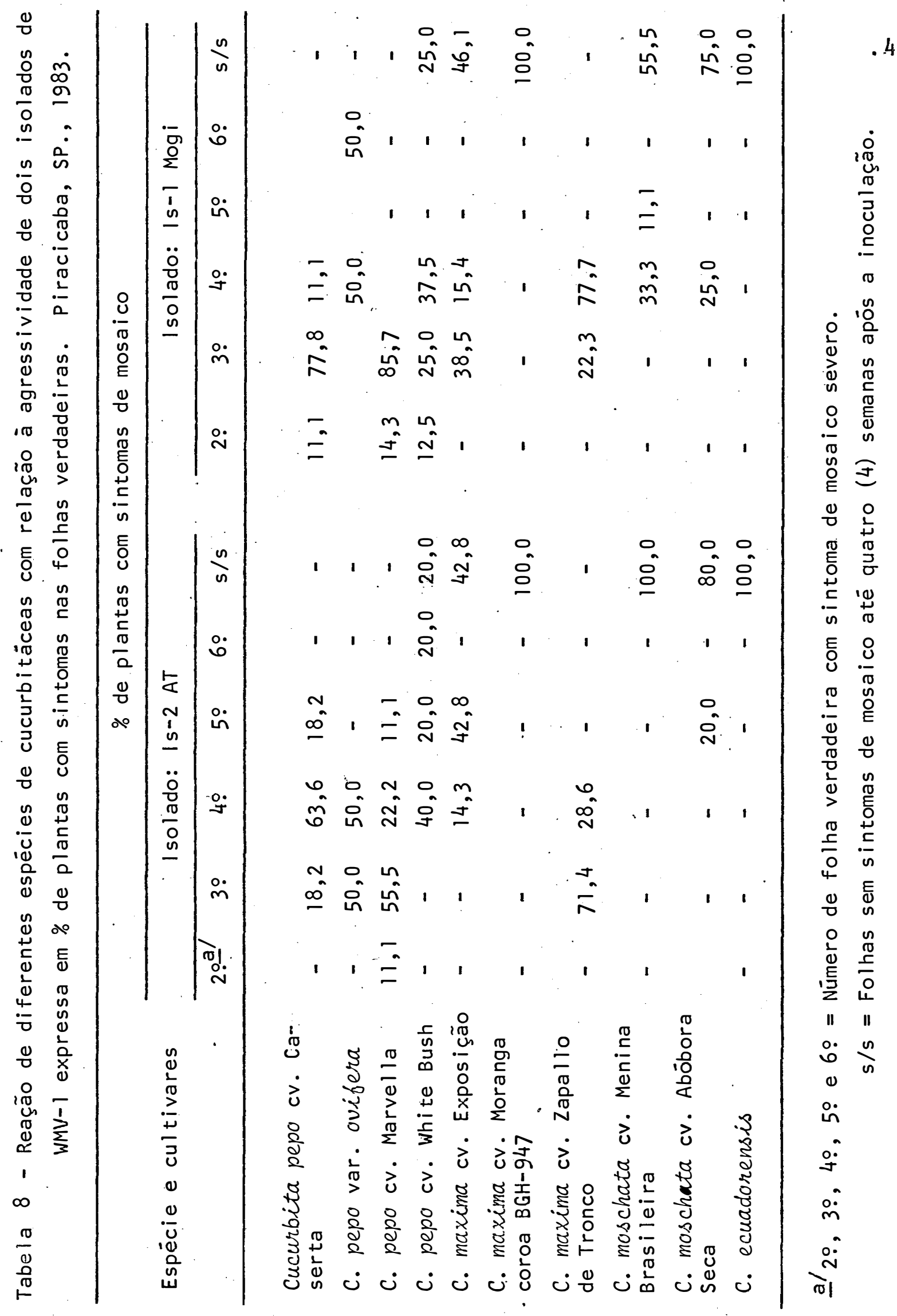


.42 .

isolados, com exceção para C. moschata cv. Menina Brasileira que foi mais suscetível ao ls-l Mogi. Já nas espécies mais suscetiveis, o Is-l Mogi causou sintomas de mosaico e deforma ção principalmente na $3^{a}$ e $4{ }^{a}$. folha verdadeira, enquanto que o Is-2 AT causou os mesmos sintomas na $4^{a}$ e 5 ? folha. Com ba se nesses resultados, optou-se pelo ls-l Mogi para os t.raba lhos posteriores de avaliação de resistência para discriminar de maneira precoce, as variedades resistentes e suscetiveis ao WMV-1.

Sob o ponto de vista de seleção e estudós de herança, nem sempre é désejāvel a utilização de isolados com maior agressividade, que causando danos severos podem eliminar indiscriminadamente, materiais que possuam um nivel moderado de resistência. Nas condiçõés desse estudo, selecionou-se o isolado mais agressivo, dentre os isolados dispon veis, pois os mais fracos, utilizados inicialmente não permitiram uma discriminação satisfatōria de materiais resistentes e suscetiveis, a nivel foliar.

Com respeito a esse teste de patogenicidade, a manifestação'mais precoce dos sintomas pode ser função somente da agressividade; contudo não se descarta a possibilidade de se tratar de uma função da concentração do inōculo. Para se confirmar tal hipötese há necessidade de se utilizar técnicas capazes de quantificar a concentração do inōculo, como a 
microscopia eletrônica ou a utilização de um hospedeiro diférencial que reaja ao WMV-l com lesões locais. Nesse ültimo ca so, existe a linhagem B63-3 de melão (WEBB, 1963) que apresenta esse tipo de reação. Contudo, essa linhagem ainda não é suficientemente homozigota para a característica, sendo necessário melhorá-la nesse sentido, antes que possa ser utilizada satisfatoriamente para esse fim.

\subsection{Fontes e tiPOS DE RESISTÊNCIA AO WMV-1}

Para a seleção de fontes de resistência ao WMV- 1 foram avaliadas 39 introduções e cultivares de C. moschata alēm de uma introdução de C. ecuadorensis. Num primeiro experimento, destinado a discriminar somente o material mais suscetivel, foram obtidos os seguintes resultados, mos: trado na Tabela 9.

As cultivares elou introduções que apresentaram maiores niveis de resistencia (inferior a 3,0) foram testados num segundo experimento, dessa vez com um nümero maior de plantas, para confirmar sua potencialidade como fontes de resistência. Os dados obtidos no primeiro e no segundo experimento, para esses materiais, podem ser comparados na Tabela 10 . 
Tabela 9 - Reação de cultivares e/ou introdução ao WMV-l, expressa em nível médio de resistência. Piracicaba, SP., 1984.

\begin{tabular}{|c|c|c|c|}
\hline $\begin{array}{l}\text { Cödigo do } \\
\text { IGEN* }\end{array}$ & $D$ e $n \circ m i n a c ̧ \tilde{a} \circ$ & $\begin{array}{l}\text { Nível } \\
\text { méd io }\end{array}$ & $\begin{array}{c}\text { No. plantas } \\
\text { testadas }\end{array}$ \\
\hline 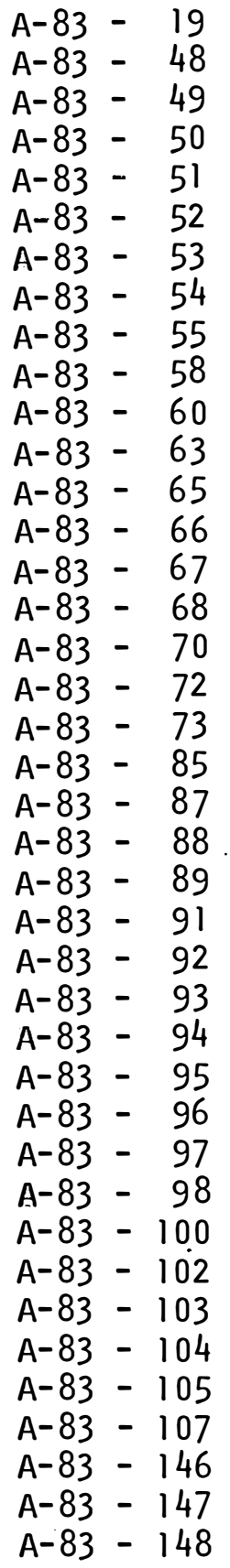 & $\begin{array}{l}\text { Pumpkin King of Mammoth } \\
\text { Aböbora Seca } \\
\text { Aböbora } \\
\text { Aböbora } \\
\text { Aböbora } \\
\text { Aböbora } \\
\text { Aböbora } \\
\text { Jerimum Vermelho } \\
\text { Jerimum Polpa Vermeiha } \\
\text { FunAl } \\
\text { Aböbora para doce } \\
\text { Chirimen } \\
\text { Futtsu Early Black } \\
\text { Chirimen } \\
\text { Chirimen } \\
\text { Shirokikuza } \\
\text { Matsudoshiro } \\
\text { Shishigatami } \\
\text { Tsurukubi } \\
\text { Aböbora } \\
\text { Jerimum de leite } \\
\text { Jerimum de leite } \\
\text { Jerimum de leite } \\
\text { Jerimum de leite } \\
\text { Jerimum de leite } \\
\text { Jerimum de leite } \\
\text { BGH-4454 } \\
\text { BGH-4360 } \\
\text { BGH-4453 } \\
\text { Aböbora } \\
\text { Butternut } \\
\text { Butterbush } \\
\text { Menina Brasileira } \\
\text { Menina Brasileira } \\
\text { Menina Brasileira } \\
\text { Menina Brasileira } \\
\text { Menina Brasileira (Agrof) } \\
\text { Squash Walthan Butternut } \\
\text { Squash Puritan } \\
\text { C. ecuadorensis }\end{array}$ & $\begin{array}{l}3,20 \\
4,20 \\
4,50 \\
4,62 \\
3,43 \\
4,80 \\
4,00 \\
2,71 \\
3,12 \\
1,25 \\
2,71 \\
3,25 \\
3,44 \\
3,43 \\
3,67 \\
3,00 \\
2,37 \\
4,14 \\
2,60 \\
2,00 \\
3,62 \\
4,00 \\
4,33 \\
3,00 \\
3,00 \\
3,25 \\
3,57 \\
3,33 \\
3,25 \\
3,25 \\
3,00 \\
3,57 \\
4,00 \\
1,43 \\
4,62 \\
3,33 \\
2,89 \\
4,14 \\
4,83 \\
1,00\end{array}$ & $\begin{array}{l}5 \\
5 \\
8 \\
8 \\
7 \\
5 \\
8 \\
7 \\
8 \\
4 \\
7 \\
4 \\
9 \\
7 \\
6 \\
9 \\
8 \\
7 \\
5 \\
7 \\
8 \\
7 \\
9 \\
8 \\
4 \\
4 \\
7 \\
6 \\
8 \\
4 \\
7 \\
7 \\
7 \\
7 \\
8 \\
6 \\
9 \\
7 \\
6 \\
4\end{array}$ \\
\hline
\end{tabular}

*Cōdigo da coleção de Cucurbitāceas pertencentes ao Setor de Melhoramen to de Hortaliças do Instituto de. Genética, ESALQ/USP. 
.45.

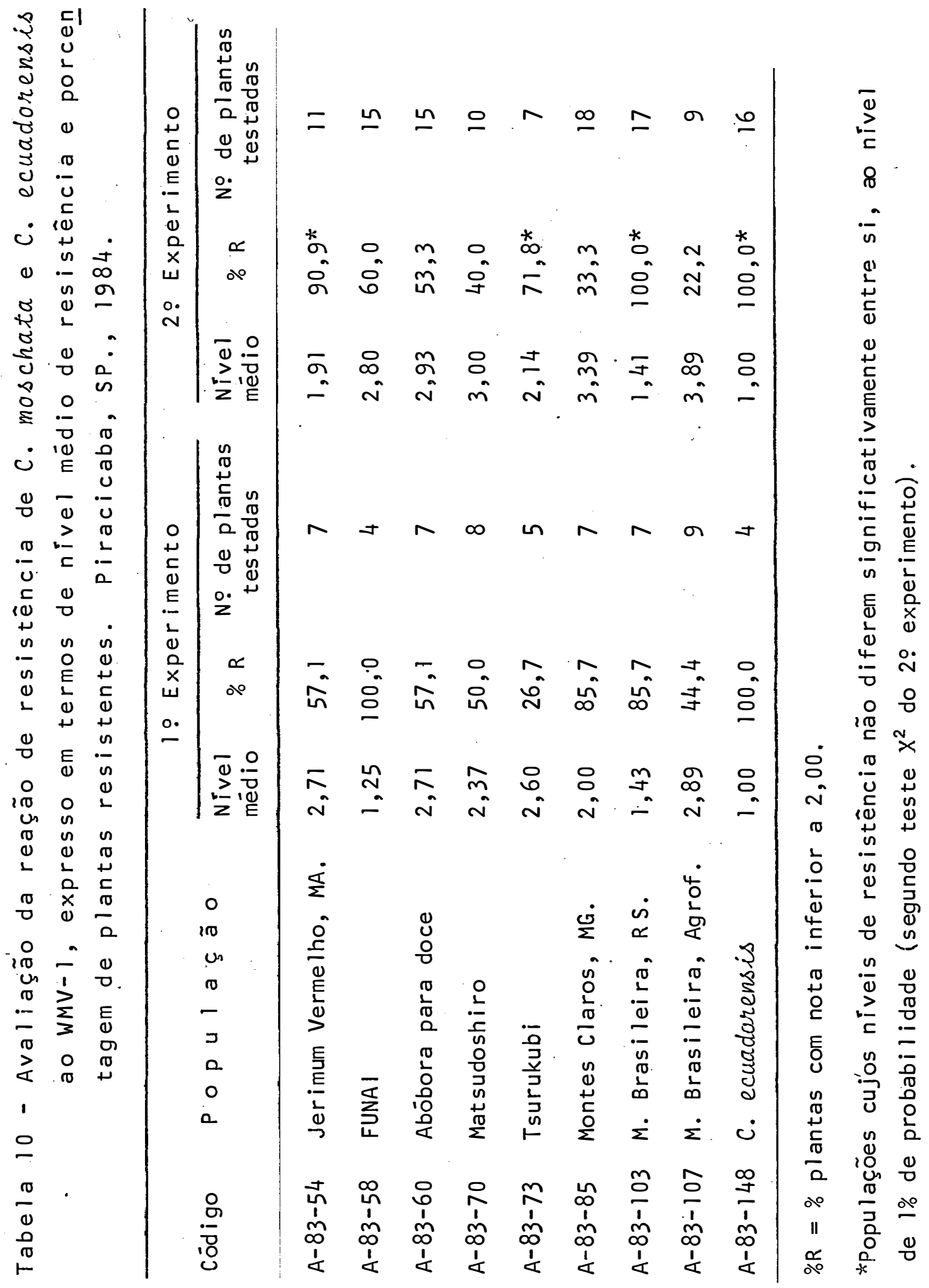


Como pode ser visto na Tabela 10 , as, populações de Cucurbita sp., que apresentaram maior nivel de resistência (nível médio inferior a 2,00) foram, em geral, aquelas que possuiram a maior porcentagem de plantas resistentes. Entretanto, essa populações consideradas promissoras como. fontes de resistência, segundo o teste $x^{2}$ (qui-quadrado) ao nivel de $1 \%$ de significância, nem sempre apresentaram $100 \%$ de plantas resistentes. Isso evidencia a variabilidade existente den tro das populações testadas, ou seja, as populações consideradas resistentes também apresentaram uma certa frequência de plantas suscetiveis. Desse modo, as populações Jerimum Vermelho, MA (A-83-54)., Tsurukubi (A-83-73) M. Brasileira, RS. (A-83-103) e C. ecuadorensis $(A-83-148)$, além de poderem ser utilizadas como fontes de resistência em cruzamentos interva rietais ou mesmo interespecíficos, também poderiam ser melhoradas quanto ao seu próprio nível de resistência, aumentando-lhes a frequência de plantas resistentes. A população de C. ecuadorensis mostrou-se altamente resistente ao WMV-1, o que concorda com os resultados obtidos por PROVVIDENT et alii (1978).

Existem algumas discordâncias entre os resultados obtidos no primeiro e no segundo experimento, como na introdução Montes Cląros, MG $(A-83-85)$ que baixou sua porcen tagem de plantas resistentes de $85,7 \%$ para $33,3 \%$ ou ao contrá rio, como no caso da cv. Tsurukubi que subiu de $26,7 \%$ para 
71,8\%. Tais casos podem ser explicados pelo menor nümero de plantas utilizados no primeiro experimento. Desse modo,as con clusões foram tomadas com base no segundo experimento,que por ter sido conduzido com um maior nūmero de plantas, pode ser considerado como mais preciso.

Plantas que não desenvolveram sintomas com a inoculação do WMV-I, portanto consideradas resistentes, foram testadas quanto à presença de vírus de modo a verificar se eram realmente resistentes ou se tratavam de escape de inoculação. Desse modo, plantas de C. pepo (padrão de suscetibili dade) foram retroinoculadas como extratos provenientes dessas plantas, na tentativa de se recuperar o virus. Quatro semanas após o retroinoculação, praticamente todas as plantas de $C$. pepo apresentavam os sintomas típicos da virose, com exceção daquelas retroinoculadas com extrato de folhas de C. ecuadorensis. Nesse tratamento, as plantas só vieram a manifestar sintomas na 8 . semana. Tais resultados demonstraram que as plantas eram realmente resistentes e não escape à inoculação.

Através dos resultados desse enisaio pode-se apresentar hipótese sobre os tipos de resistência apresentado por cada população. Como foi dito, com 4 semanas praticamente todas as plantas retroinoculadas apresentaram sintomas severos de mosaico e de deformação, indicando que os hospedeiros resistentes abrigavam o virus sem interferir sua multipli 
caçao. São portanto tolerantes, segundo a classificação de RUSSEL (1978). O vírus multiplica-se normalmente no hospedeiro, mas, sem lhe causar sintomas ou danos severos. Já plan tas retroinoculadas com extrato de folhas de $C$. ecuadorensis sö mostraram sintomas com 8 semanas. Portanto, em relação as populações de C. moschata, C. ecuadorensis afetou a multiplicação normal do vírus, pois até conseguir uma concentração de vírus que causasse os mesmos sintomas em $C$. pepo, o inóculo necessitou o dobro do tempo. Com issu, $C$. ecuadorensis é tida como resistente à multiplicação do vírus, segundo a clas sificação de RUSSEL (19.78).

PROVVIDENT et alii (1978), que considerou $C$. ecuadorensis como espécie altamente resistente ao WMV-l e WMV-2, não recuperou os sintomas em plantas de. C. pepo retroinoculadas. Contudo, isso pode ser explicado pela demora em se obter tais resultados. Avaliações antes de 8 semanas realmente não revelariam o aparecimento dos sintomas.

Contudo, tais hipótesés necessitam ser melhor estudadas, uma vez que esses resultados também poderiam ser obtidos com diferentes concentrações de inóculo. Para tanto, há necessidade de se lançar mão de outras técnicas (como a mi croscopia eletrônica e/ou hospedeiro com reação local ao WMV-1, já discutido no item 4.2.) que possam quantificar essas concentrações. 
C. ecuadorensis e recomendada por esses mesmos autores como uma das fontes de resistencia mais promissoras por sua resistência ao CMV, WMV-1, WMV-2 e outras viroses. 0 tipo de resistência apresentado por essa espécie poderia ser explorado em programas de melhoramento de C. moschata e C. ma xima, uma vez que os cruzamentos entre $C$. ecuadorensis e essas duas espécies são satisfatórias (GREBER e HERRINGTON,1980).

Embora existam fontes de resistência promissoras dentro de $C$. moschata e $C$. maxima, conforme consta na Tabela 10 , sua resistência é do tipo tolerância. Segundo BAWDEN (1964), o. uso de cultivares tolerantes representa um perigo potencial, uma vez que elas podem se tornar fontes de infecção para outras espécies suscetíveis para outras espécies suscetiveis. No entanto, esse fator assume importância secun dăria visto que, uma cultivar resistente, mesmo que tolerante, tem um grande valor econômico.

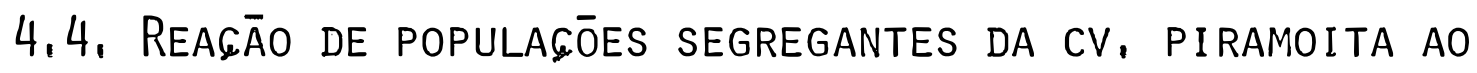 WMV-1}

A reação das populações segregantes da cv. Piramoita ao WMV-I pode ser observada na Tabela 11.

A interpretação dos dados apresentados na Tabe la il podem ser melhor visualizados através dos grä́ficos a- 
Tabela 11 - Reaçāo de populações segregantes da cv. Piramoita ao WMV-1, ex pressa em nível.médio de resistência, porcentagem de plantas resistentes e pelos resultados do teste qui-quadrado. Piraci caba, SP., 1984 .

\begin{tabular}{|c|c|c|c|c|c|}
\hline Pop̣ul ação & $\begin{array}{l}\text { Nivel } \\
\text { médioll }\end{array}$ & $\% R \leq 1$ & $x^{2} 3 /$ & Interpretaçāo & estatistica \\
\hline$M_{i}$ Brasileira C2 & 2,67 & 52,81 & - & $\mathrm{bc}$ & \\
\hline$F_{1} R C_{1}$ & 3,43 & 32,00 & $20,10 * *$ & \multicolumn{2}{|r|}{$g h$} \\
\hline$F_{2} R C_{1}$ & 3,81 & $2.0,42$ & $48,97 * *$ & \multicolumn{2}{|r|}{$i$} \\
\hline$F_{1} R C_{2}$ & 2,97 & 42,73 & $4,91 *$ & \multicolumn{2}{|l|}{ de } \\
\hline $\mathrm{F}_{2} \mathrm{RC}_{2}$ & 3,10 & 44,03 & $4,31 *$ & de & . \\
\hline $\mathrm{F}_{3} \mathrm{RC}_{2}$ & 3,27 & 41,54 & $5,93 *$ & \multicolumn{2}{|c|}{ def } \\
\hline$F_{4} R_{2}$ & 3,83 & 29,06 & $28,93 * *$ & \multicolumn{2}{|c|}{$g h$} \\
\hline$F_{1} R C_{3}$ & 3,86 & 25,40 & $40,76 * *$ & \multicolumn{2}{|r|}{ hi } \\
\hline $\mathrm{F}_{2} \mathrm{RC}_{3}$ & 3,42 & 35,68 & $14,54 * *$ & \multicolumn{2}{|c|}{$\mathrm{e} f \mathrm{~g}$} \\
\hline $\mathrm{F}_{1} \mathrm{RC}_{4}$ & 2,72 & 52,00 & $0,02 \mathrm{~ns}$ & \multicolumn{2}{|l|}{ bcd } \\
\hline $\mathrm{F}_{2} \mathrm{RC}_{4}$ & 2,20 & 66,07 & $3,29 \mathrm{~ns}$ & \multicolumn{2}{|l|}{$a b$} \\
\hline $\mathrm{F}_{3} \mathrm{RC}_{4}$. & 2,54 & 61,26 & $2,26 . \mathrm{ns}$ & \multicolumn{2}{|l|}{$a b$} \\
\hline $\mathrm{F}_{4} \mathrm{RC}_{4}$ & 3,01 & 48,86 & $0,75 \mathrm{~ns}$ & \multicolumn{2}{|l|}{$c d$} \\
\hline $\mathrm{F}_{5} \mathrm{RC}_{4}$ & 3,61 & 33,81 & $20,04 * *$ & \multicolumn{2}{|r|}{$\mathrm{fg}$} \\
\hline $\mathrm{F}_{6} \mathrm{RC}_{4}$ & 2,22 & 71,62 & $13,99 * *$ & - $a$ & \\
\hline
\end{tabular}

1/Nivel médio de resistência = Média ponderada.

$2 / \% R=$ Porcentagem de plantas resistentes (plantas com notas 1 e 2).

3/Teste $x^{2}$ = Comparação da M. Brasileira com os demais tratamentos em Tabelas de contingência $2 \times 2$.

$4 /$ Interpretação estatística de todas as comparações possíveis entre os tratamentos, através do teste $x^{2}$ - Tabela de contingência $2 x 2$.

**Significativo ao nivel de $1 \%$ de probabilidade.

*Significativo ao nivel de $5 \%$ de probabilidade. $n s=$ năo significativo. 
baixo (Figuras 2 e 3 ).

Tomando como base de comparação a cv. Menina Brasileira, que foi o progenitor recorrente e,portanto, o par drão de resistência para esse experimento, pode-se observar que de todas as populações segregantes da cv. Piramoita, somente àquelas pertencentes ao quarto retrocruzamento $\left(R C_{4}\right)$ apresentavam um nível de resistência equivalente à testemunha (Figura 3). Observou-se também (Figura 2 e Tabela 11) que as pop $\underline{u}$ lações do $\dot{R} C_{4}$ mostraram-se variāveis quanto ao nível médio de resistência $(2,22$ a 3,61$)$, não seguindo nenhum padrão de comportamento. Isso se explica pelo fato de que as populações, por não sofrerem nenhuma pressão de seleção voltada para resistência ao WMV-1, apresentam com certo equilíbrio: : dinâmico entre plantas resistentes e plantas suscetiveis. Esse equili brio poderá seguir a lei de Hardy-Weinberg,entretanto como não se conhece os alelos envolvidos no caráter de resistência,tal fato não pode ser comprovado experimentalmente.

Os resultados apresentados comprovam a hipōtese inicial de que o método de retrocruzamento recupera as caracteristicas do progenitor recorrente. Nesse caso especifi co,foram necessários quatro retrocruzamentos para se recuperar um nível de resistência ao WMV-l equivalente ao da cV. Menina Brasileira. 


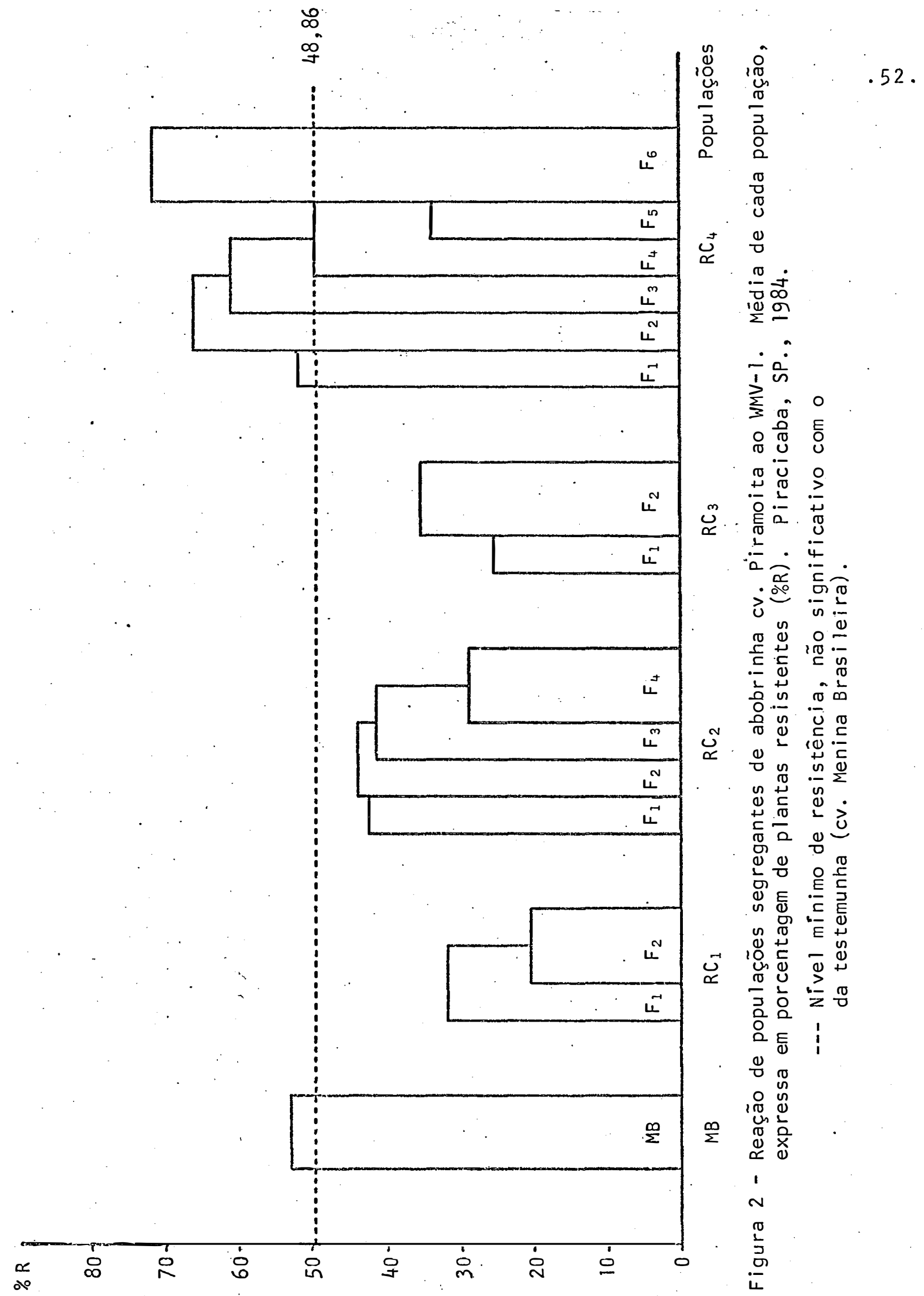


.53.
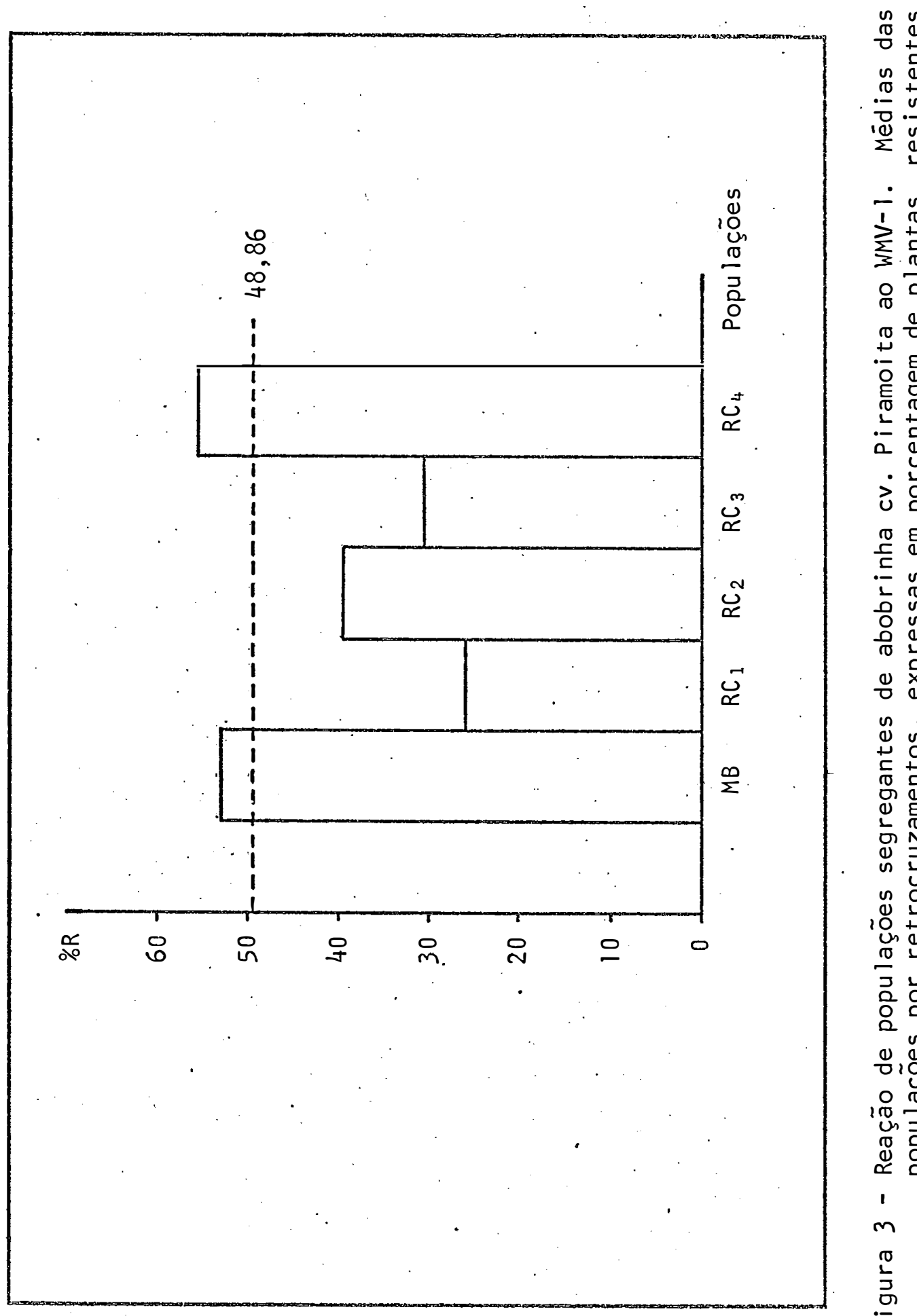

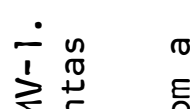

$\sum_{3} \frac{1}{\sigma} \quad 00$

응

욤

$\div$ 턴

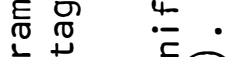

$\therefore \frac{1}{\square}$ ㄷํㅇ

$\rightarrow \frac{1}{0} \quad 0$

U 口

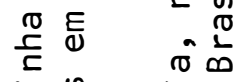

듬

年

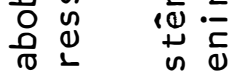

ब) $\frac{1}{x} \quad \frac{\pi}{2}$

0 0

क i 0 U

+0 D

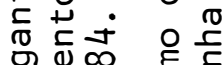

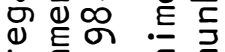

ธत

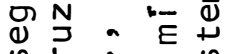

ज एँ

क O क ष

$10 \frac{1}{2}$

Uీ⿻

元苛

긍 ㅎำ:

웅

๑ ע.:-

Tigna

100

ํํำ

(1) ㅇำ

I

$m$

ฮ 
.54.

\section{4,5, REAৎĀO DE PROGÊNIES DE MEIOS-IRMĀOS DE ABŌBRINHA CV, PIRAMOITA AO WMV-1}

os resultados de reação das progênies das popu lações $\mathrm{F}_{6} \mathrm{RC}_{4}, \mathrm{~F}_{7} \mathrm{RC}_{4}, \mathrm{~F}_{8} R C_{4}, \mathrm{~F}_{9} R C_{4}$ e $\mathrm{F}_{1} \mathrm{RC}_{4}$ ao WMV-l são mostrados na Tabela 12 e a estimativa dos parâmetros genéticos na Tabela 13. A anālise de variância encontra-se na Tabela 14 do apêndice.

A aṇālise da variância rẹelou uma alta unifor midade entre as progênies de cada população. Os coeficientes de variação genētica entre progênies, estimados atravēs da esperança matemática do quadrado médio, em geral, também se mostraram homogêneos entre si. 0 coeficiente de variação genētica é utilizado para estimar a variabilidade genética existente numa população. Os valores obtidos nesse trabalho podem ser considerados como baixos, indicando pouca variabilidade genētica, o que pode significar uma maior dificuldade no melhoramento para resistência ao vírus.

No experimento de progênies observou-se uma frequência muito alta de plantas suscetíveis, o que não era esperado, uma vez que todas as progênies eram de populações do 4 ? retrocruzamento, que anteriórmente. jā tinham se mostrado tão resistentes quanto seu progenitor recorrente, a cv. M. Brasileira. Duas causas podem ter contribuído: a altera- 


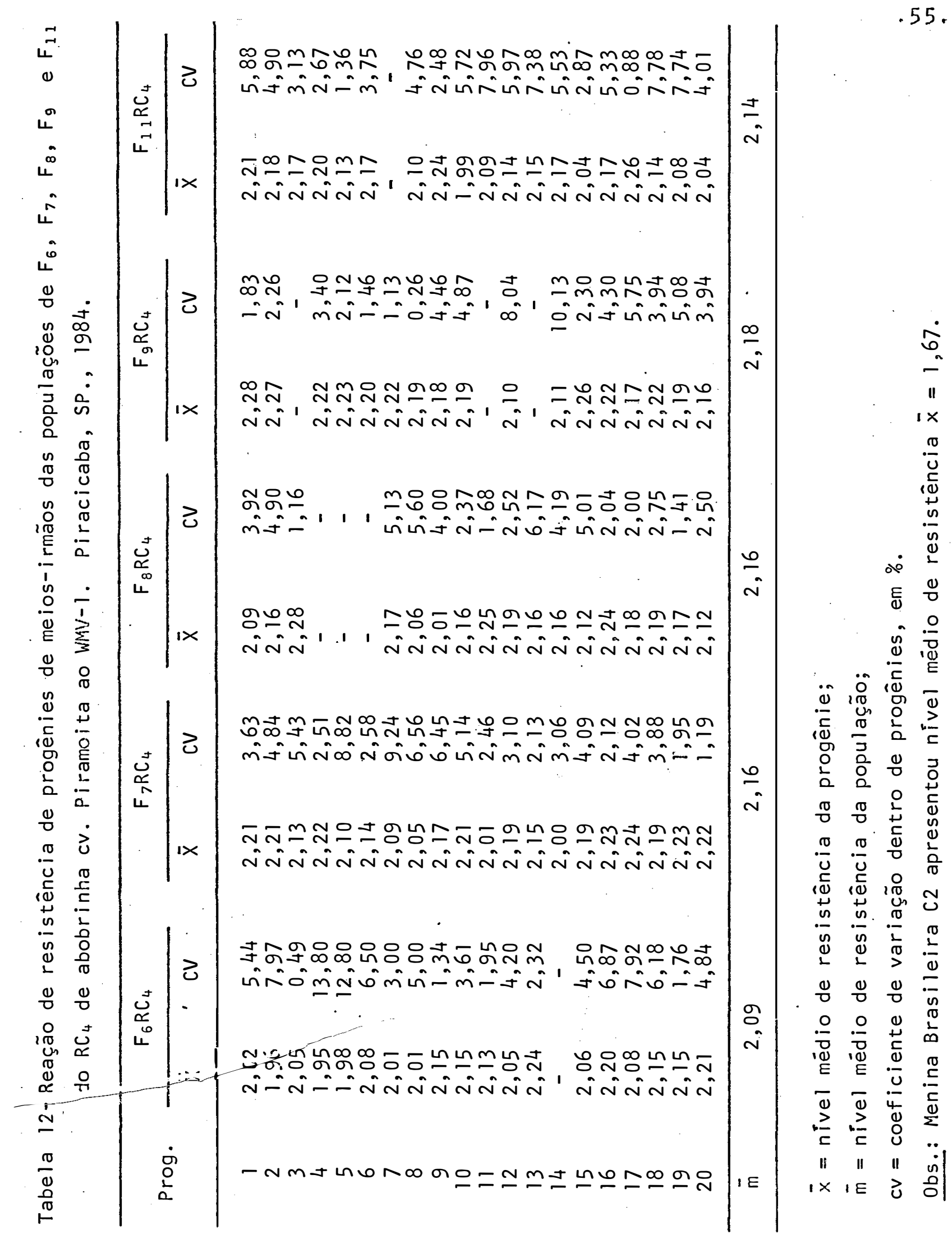


.56 .

Tabela 13 - Estimativas de parâmetros genéticos da reação de resistência ao WMV-1, referente a progênies de meios irmãos de cinco populações segregantes de abobrinha cv. Piramoita (C. moschata). Piracicaba, SP., 1984 .

\begin{tabular}{cccccc}
\hline & $\mathrm{F}_{6} R C_{4}$ & $\mathrm{~F}_{7} R C_{4}$ & $\mathrm{~F}_{8} R C_{4}$ & $\mathrm{~F}_{9} R C_{4}$ & $\mathrm{~F}_{11} R C_{4}$ \\
\hline$\hat{\sigma}_{\mathrm{P}}^{2}$ & 0,26 & 0,23 & 0,29 & 0,11 & 0,22 \\
$\hat{\sigma}_{\mathrm{e}}^{2}$ & 0,81 & 0,61 & 0,12 & 0,94 & 0,38 \\
$\hat{\sigma}_{\mathrm{d}}^{2}$ & 8,19 & 6,05 & 6,20 & 5,32 & 7,16 \\
$\hat{\sigma}_{\mathrm{A}}^{2}$ & 1,04 & 0,93 & 1,15 & 0,44 & 0,88 \\
$\hat{\sigma}_{\mathrm{F}}^{2}$ & 9,26 & 6,89 & 6,61 & 6,37 & 7,76 \\
\hline$\hat{\mathrm{h}}^{2}$ & 11,23 & 13,50 & 17,40 & 6,91 & 19,10 \\
$\mathrm{CV}$ & 2,44 & 2,22 & 2,49 & 1,52 & 2,19 \\
\hline
\end{tabular}

$\begin{aligned} \hat{\sigma}_{p}^{2}= & \text { Variância genētica entre progênies ao nível de } \\ & \text { indivíduos }\left(x, 10^{-2}\right) ;\end{aligned}$ $\hat{\sigma}_{e}^{2}=$ Variância ambiental entre parcelas $\left(x, 10^{-2}\right)$;

$\hat{\sigma}_{d}^{2}=$ Variância fenotípica dentro de progênies $\left(x .10^{-2}\right)$;

$\hat{\sigma}_{\mathrm{A}}^{2}=$ Variância genética aditiva $\left(x \cdot 10^{-2}\right)$;

$\begin{aligned} \hat{\sigma}_{F}^{2}= & \text { Variância fenotípica entre médias de progênies } \\ & \left(x .10^{-2}\right) ;\end{aligned}$

$\hat{h}^{2}=$ Coeficiente de herdabilidade, sentido restrito $(\%)$.

$C V=$ Coeficiente de variação genética entre:progênies (\%). 
ção na patogenicidade do isolado de WMV-l (vide item 4.l.) e/ou menor vigor das plantas. No 10 caso a maior agressividade do isolado, aliado às condições de inoculação artificial, torna-se uma situação inexistente na natureza. Desse modo, descartam-se plantas que teriam alto potencial de resistência. Esta situação agravou-se ainda mais, dado a menor ocorrência de chuvas durante o período de experimentação (vide Figura 1) ocasionou um menor vigor no desenvolvimento das plantas (mesmo com auxilio de irrigação), de modo que os sintomas da viro se foram ainda mais acentuados. Para esse tipo de estudo é necessārio alterações na metodologia como redução da concen tração do inōculo, inoculações mais tardias ou mesmo utiliza ção de inoculação naturạl. .

o coeficiente de variação dentro de progênies envolve efeitos ambientais e genéticos. Quanto maior o coe ficiente de variação maior será a variação genética dentro de progênies. Nesse caso, as progênies apresentaram baixo coeficiente de variação e embora existam progênies que se destạ quem das demais, não é recomendável a seleção dentro das progênies. Ramallo (1977), citado por MELo (1983) estudando a eficiência de alguns processos de seleção intrapopulacional no milho, sugere que na seleção entre e dentro de familias de meios-irmãos, deve-se aplicar uma maior pressão de seleção en tre do que dentro, visto que a seleção entre familias é.basea 
da em médias de värias repetições que asseguram uma maior precisão de médias do que nas observações individuais que constituem as unidades de seleção dentro de familias. Contudo, de vido ao pequeno número de progênies avaliadas, estas prestaram-se somente para estimação de parâmetros genéticos, já que altas pressões de seleção em populações pequenas podem resultar em problemas relacionados ao tamanho efetivo da população, aumentando a probabilidade de perdas de genes importantes devido à oscilação genētica (MELo, 1983).

As estimativas dos coeficientes de herdabilida de no sentido restrito ao nível de médias de progênies, em to das as populações, mantiveram-se baixos, variando de $6,91 \%$ a $19,10 \%$ (Tabela 13), o que indica a necessidade da utiliżação de métodos de melhoramento mais precisos. GARCIA S. (1984) re comenda, ao se proceder seleção com base na média de progênies, aumentar o número de repetições do ensaio ou o número de observações dentro da parcela, o que implicará num aumento do coeficiente de herdabilidade, direcionando melhor a estratēgia·de seleção a ser adaptada. 


\section{CONCLUSŌES}

Com base nos resultados obtidos no presente trabalho estabeleceram-se as seguintes conclusões:

1) Dentre os isolados coletados, o Virus do Mo saico da Melancia raça-l (WMV-1) foi o que predominou.

2) As fontes de resistência mais promissoras de Cucurbita moschata avaliadas foram as cultivares Menina Bras leiray RS e Tsurukubi, com $100 \%$ e $71,8 \%$ de plantas resistentes, respectivamente, e a introdução Jerimum Vermelho, MA,com $90,9 \%$ de plantas resistentes.

3) Cucurbita ecuadorensis mostrou alto nivel de resistência $(100 \%$ de plantas resistentes $)$.

4) 0 mētodo de melhoramento atravēs de retrocruzamentos foi eficiente em recuperar as características do progenitor recorrente, a cv. Menina Brasileira. Quatro retro 
cruzamentos foram suficientes para recuperar um nivel de resistência equivalente ao da cv. Menina Brasileira. 0 progeni tor recorrente apresentou $52,8 \%$ de plantas resistentes, enquanto a média das populações segregantes do quarto retrocrú zamento foi de $55,60 \%$.

5) Os coeficientes de variação genética entre progênies variaram de $1,52 \%$ a $2,49 \%$ e podem ser considerados baixos, indicando pouca variabilidade genética. As estimati vas dos coeficientes de herdabilidade, no sentido restrito,ao nivel de médias de progênies, também mantiveram-se baixos,oscilando entre $6,91 \%$ e $19,10 \%$, indicando a necessidade de util i zação de métodos de melhoramento mais precisos para a seleção de plantas resistentes ao WMV-l em populações de Piramoí t.a. 


\section{BIBLIOGRAFIA}

ADLERZ, W.C., 1972. Momordica charantia as a source of watermelon mosaic virus 1 for Cucurbit crops in Palm Beach Country, Florida. Plant Disease Reporter. Washington, D.C.,56(7):563-564.

ALbUQUerque, F.C., H. IKEDA e A.S. COSTA, 1972. Ocorrência do virus do mosaico da melancia na região de Belém. Rev. Olericultura, Fortaleza, 12:94.

ANDERSON, C.W., 1954. Two watermelon mosaic virus strains from Central florida. Phytopathology. Lancaster, 44:198-202.

ÁVILA, A:C., 1982. Viroses de Cucurbitāceas. Inf. Agropec. Belo Horizonte, $8(85): 52-54$.

ĀVILA, A.C.; P.T. DELLA VECCHIA, M.T. LIN; L.O.B. d'OLIVEIRA e J.P. de ARAOJo, 1984. Identificação do Vírus do Mosaico da Melancia em Melão (Cucumis melo) e melancia. (Citrullus lanatus) na região do Submédio São Francisco. Fitopatologia Brasileira, Brasilia, 9:113-117. 
BAWDEN, F.C., 1964. Plant viruses and virus diseases. 4. ed. Nova York, Ronald Press. $361 \mathrm{p}$.

COHEN, S. e F.E. NITZANY, 1963. Identify of viruses affecting cucurbits in Israel. Phytopathology. Lancaster, $53: 193-196$.

COSTA, A.S., E.W. KITAJIMA e H. NAGAI, 1972. Alguns vírus que afetam o pepino em São Paulo. Rev. de olericultura. Fortaleza, 12:100-101.

CUPERTINO, F.P.; C.L. COSTA; E.W. KITAJIMA; J.K.A. MATTOS E M.T. ARAÚJ0, 1974. Viroses de Cucurbitāceas no Distrito Federal. in Anais do VII Congresso da Sociedade Brasileira de Fitopatologia. Brasilia, DF. 48-51.

DELLA VECCHIA, P.T. e AVILA, A.C., 1984. Herança da resistência ao Vírus do Mosaico da Melancia-l (WMV-1) em melão. in Resumos do XXIV Congresso Brasileiro de olericultura. Jaboticabal, p.102.

DEMSKI, J.W. e J.H. CHALKLEY, 1972. Effect of Watermelon Mosaic Virus on Yield and Marketability of Summer Squash. Plant Disease Reporter. Washington, D.C.,56(2):147-150.

EBRAHIM-NESBAT, F., 1974. Distribution of Watermelon Mosaic Viruses 1 and 2 in Iran. Phytopathologische Zeitschrift. Berlin, $79: 352-358$.

FISCHNALER, D.F., 1972. Identification" and distribution of Watermelon Mosaic Virus l in El Salvador. PZant Disease Reporter. Washington, D.C., 56(5):437-440. 
GARCIA S., M.J., 1984. Resistência ao Mosaico da Melancia raça 1 e sua herança em moranga Cucurbita maxima Duch. Piracicaba, ESALQ/USP. 76p. (Dissertação de Mestrado).

GERALDI, 1.0., 1977. Estimação de parâmetros genēticos de caracteres do pendão em milho (Zea mays, L.) e perspectivas de melhoramento. Piracicaba, ESALQ/USP. 103p. (Dissertação de Mestrado).

GREBER, R.S. e M.E. HERRINGTON, N., 1980. Reaction of interespecific hybrids between Cucurbita ecuadorensis, C. maxima and $C$. moschata to inoculation with cucumber mosaic virus and watermelon mosaic virus 1 and 2 . Australian Plant Pathology, 1980, 9(1):1-2. In: Rev. Plant Pathology, 1127, 60(2):96. 1981.

GROGAN, R.G.; D.H. HALL e K.A. KIMBLE, 1959. Cucurbit mosaic viruses in California. Phytopathology. Lancaster, $49: 366-376$.

IGLESIAS, A.P. e P.A. GON.ZALEZ, 1973. Estudio de una estirpe del Mosaico de La Sandia. Ministerio de Agricultura, Madrid. Monografia n? 20 .

LÁSTRA, R., 1968. Occurrence of Cucurbit Viruses in Venezuela. Plant Disease Reporter. Washington, D.C., $52(2): 171-174$.

LIN, M.T.; E. KITAJIMA; F.P. CUPERTINO e C.L. COSTA. Watermelon Mosaic Virus strain occurring in bush squash in Federal District. Ciência e Cultura, São Paulo, 28:199 (Resumo). 
.64.

LOVISOLO, 0. e V. LISA, 1983. Virosi e Micoplasmosi delle Cucurbitaceae (Levirosi della Pianteartive). L'Italia Agricola, Roma, $120(1): 58-72$.

MALUF, W.R.; I.S. SILVA e W.M. MOURA, 1984. Herança da resistência ao vírus do Mosaico da Melancia-l (WMV-1) em moranga Cucurbita maxima Duch. In Resumos do XXIV Congresso Brasizeiro de olericultura. Jaboticabal, p.103.

MCLEAN, D.M. e H.M. MEYER, 1961. Survey of cucurbit viruses in the lower Rio Grande Valley of Texas. Plant Disease Reporter. Washington, D.C., 45:137-139.

MELO, I.S., 1983. Seleção massal e de progênies de meios i rmãos em cebola (Allium cepa L.) para resistência a Colletotrichum gloeosporioides Penz. |Sensu ARX, 1957|. Piracicaba, ESALQ/USP, 103p. (Dissertação de Mestrado).

MILNE, K.S. e R.G. GROGAN, 1969. Characterization of Watermelon Mosaic Virus strains by serology and other properties. Phytopathology. Lancaster, 59:809-818.

MILNE, K.S.; R.G. GROGAN e K.A. KIMBLE, 1969. Identification of viruses infecting cucurbits in California. Phytopathology. Lancaster, $59: 819-825$.

NELSON, M.R.; R.M. ALLEN e D.M. TUTTLE, 1962. Distribution, prevalence and importance of some cantaloup virus diseases in South-Western Arizona. Plant Disease Reporter. Lancaster, D.C., 46:667-671.

NELSON, M.R.; J.A. LABORDE e H.H. MCDONALD, 1966. Cucurbit viruses on the west coast of Mexico. Plant Disease Reporter. Washington, D.C., 50(12):947-950. 
PAIVA, J.R., 1980. Estimativas de parâmetros genéticos em seringueira (Hevea sp) e perspectivas de melhoramento. Piracicaba, ESALQ/USP, 92p. (Dissertação de Mestrado).

PIMENTEL GOMES, F., 1981. Curso de Estatistica Experimental. 9. ed. Piracicaba, Ed. Nobel. 430p.

PROVVI DENTI, R. e W.T. SCHROEDER, 1970. Epiphytotic of Watermelon Mosaic among Cucurbitaceae in Central New York in 1969. Plant Disease Reporter. Washington, D.C., $54(9): 744-748$.

PROVVIDENTI, R.; R.W. ROBINSON E H.M. MUNGER, 1978. Resistence in feral species to six viruses infecting Cucurbita. Plant Disease Reporter. Washington, D.C., $62(4): 326-329$.

PURCIFULL, D.E. e E. HIEBERT, 1979. Serological distinction of Watermelon Mosaic Virus isolates. Phytopathology. Lancaster, 69:112-116.

QUIOT, F.; J.B. KAAN e M. BERAMIS, 1971. Identification d'une souche de la mosaique de la Pastéque (Watermelon Mosaic Virus l) aux Antilles Française. Ann. Phytopato. Paris, 3(1):125-130.

RUSSEL, G.E., 1978. Plant Breeding for Pest and Disease Resistance. Londres, Butterworths. $485 \mathrm{p}$.

SHANMUGASUNDARAM, S., M. ISHII; J.C. GILBERT e H. NAGAI, 1969. Cucurbit virus studies in Hawaii. Plant Disease Reporter. Washington, 53(1):70-74. 
.66 .

SILVA, N. da e C.P. da COSTA, 1975. Avaliação e herança da resistência ao mosaico da melancia em pepino (Cucumis sativus L.l. Rev. de Olericultura. Botucatu, 15:12.

SILVA, N. da, 1977. Herança da resistência ao mosaico da melancia (WMV-1) em pepino (Cucumim sativus L.). Piracicaba, ESALQ/USP. 82p. (Tese de Doutoramento).

SMITH, K.M., 1960. PZant Viruses. 3. ed. Methuen e Co. L.tda. Londres. $209 p$

SMITH, K.M., 1974. PZant Viruses. 4! ed. Londres. Chapman e Hall. $211 \mathrm{p}$

SNEDECOR, G.W. e G. COCHRAN, 1973. Statistical Methods. 6. ed. E.U.A., lowa State University Press. 593p.

STEEL, R.G.D. e J.H. TORRIE, 1960. Principles and procedures of Statistics. New York, McGraw-Hill Book Company. $481 p$.

VENCOVSKY, R., 1969. Genética Quantitativa. In: KERR, W.E., org. MeIhoramento e Genética. São Paulo, Edições Melhoramento. p, 17-38.

WEBB, R.E., 1963. Local lesion hosts for some isolates of Watermelon Mosaic Virus 1. Hortscience, Virginia, $14: 265-266$.

WEBB, R.E. e H.A. SCOTT, 1965. I solation and identification of Watermelon Mosaic Viruses 1 and 2. Phytopathology. Lancaster, 55:895-900. 
WEBB, R.E.; G.W. BOHN e H.A. SCOTT, 1965. Watermelon Mosaic Viruses 1 and 2 in southern and western Cucurbit production areas. Plant Disease Reporter. Washington, D.C., $49(16): 532-535$.

WEBB, R.E., 1971. Watermelon Mosaic Viruses 1 and 2 in Squash on the Atlantic Seaboard. Plant Disease Reporter. Washington, D.C., $55(2): 132-135$.

WEBB, R., 1979. Inheritance of resistance to Watermelon Mosaic Virus 1 in Cucumis melo L. Hortscience, Virginia, $14(3): 265-266$.

WHITAKER, T.W. e G.N. DAVIS, 1962: Cucurbits World Crop Books. Londres, Leonard Hill Lt. $250 \mathrm{p}$.

ZABALA, S. e J.C. RAMALLO, 1968. El mosaico de las Cucurbitaceas. Rev. Agron. N.O. Arg. (UNT). Argentina, $6(3-4): 197-208$.

ZITTER, T.A. e J.H. TSAI, 1977. Transmission of three potyviruses by the leafminer Liriomyza sativae (Diptera:Agromyzidae). Plant Disease Reporter. Washington, D.C., $61(12): 1025-1029$. 
.68.

\section{APÊNDICE}




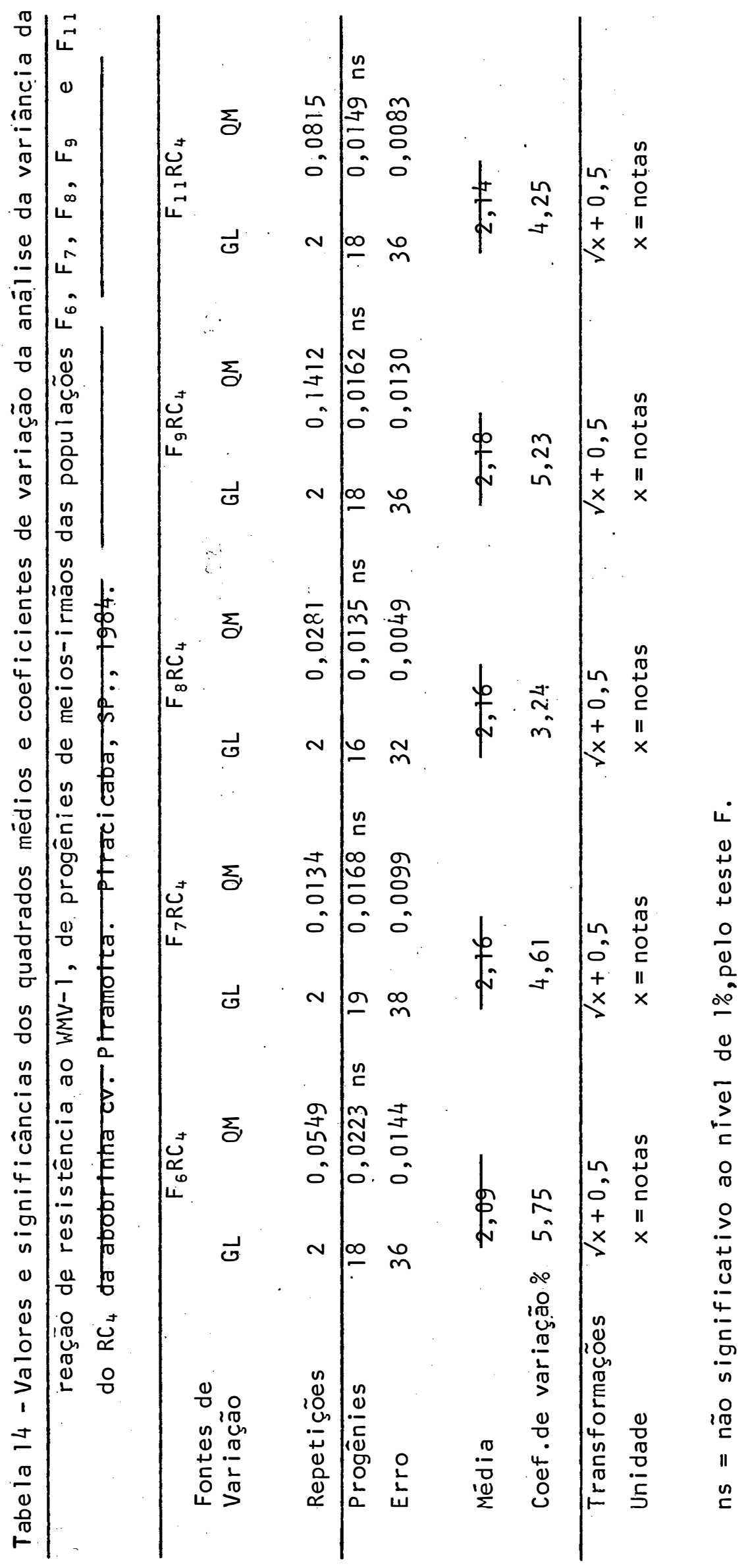

